\title{
Integrated Resistivity and Ground Penetrating Radar Observations of Underground Seepage of Hot Water at Blawan-Ijen Geothermal Field
}

\author{
Sukir Maryanto, ${ }^{1}$ Ika Karlina Laila Nur Suciningtyas, ${ }^{2}$ \\ Cinantya Nirmala Dewi, ${ }^{2}$ and Arief Rachmansyah ${ }^{3}$ \\ ${ }^{1}$ Department of Physics, Faculty of Mathematics and Science, University of Brawijaya, Malang 65145, Indonesia \\ ${ }^{2}$ Postgraduate Program of Physics, Faculty of Mathematics and Science, University of Brawijaya, Malang 65145, Indonesia \\ ${ }^{3}$ Department of Civil Engineering, Faculty of Engineering, University of Brawijaya, Malang 65145, Indonesia
}

Correspondence should be addressed to Sukir Maryanto; sukir@ub.ac.id

Received 9 December 2015; Revised 20 April 2016; Accepted 21 April 2016

Academic Editor: Yun-tai Chen

Copyright (c) 2016 Sukir Maryanto et al. This is an open access article distributed under the Creative Commons Attribution License, which permits unrestricted use, distribution, and reproduction in any medium, provided the original work is properly cited.

Geothermal resource investigation was accomplished for Blawan-Ijen geothermal system. Blawan geothermal field which located in the northern part of Ijen caldera presents hydrothermal activity related with Pedati fault and local graben. There were about 21 hot springs manifestations in Blawan-Ijen area with calculated temperature about $50^{\circ} \mathrm{C}$. We have performed several geophysical studies of underground seepage of hot water characterization. The geoelectric resistivity and GPR methods are used in this research because both of them are very sensitive to detect the presence of hot water. These preliminary studies have established reliable methods for hydrothermal survey that can accurately investigate the underground seepage of hot water with shallow depth resolution. We have successfully identified that the underground seepage of hot water in Blawan geothermal field is following the fault direction and river flow which is evidenced by some hot spring along the Banyu Pahit river with resistivity value less than $40 \Omega \mathrm{m}$ and medium conductivity.

\section{Introduction}

Indonesia has high potential of geothermal energy spread over 265 locations [1]. Since the geothermal resource exploration in Indonesia, the Blawan-Ijen geothermal field has been identified as a region with high geothermal potential approximately $110 \mathrm{MW}$. Unfortunately the Blawan-Ijen geothermal resource has not been developed for power generation until now. However, a significant rise in population and a great increase in energy and water demand lead to identifying and assessing Blawan-Ijen geothermal field for future commercial development. To determine the geothermal potential in Blawan-Ijen geothermal field, a study of subsurface conditions is required. Some geothermal researches in Blawan-Ijen have been done [2-4] but have never been done using geoelectric resistivity and ground scan penetrating radar (GPR) method.
The presence of water will reduce resistivity; meanwhile the presence of air in voids will increase subsurface resistivity $[5,6]$. If the temperature rises, the resistivity value of rocks will be smaller [7]. However, the Ground Penetrating Radar (GPR) is a noninvasive electromagnetic geophysical technique with high resolution for identifying and mapping in subsurface exploration [8]. Detectability of objects in the ground depends upon several geological factors such as hot water, salt water, mineralogical clay, soils, and other electrical properties through conduction losses.

Delineation of underground seepage using geophysical methods has gained wide interests in the past few decades. Geoelectrical resistivity and GPR are the most frequently used geophysical techniques in exploring the groundwater. It offers quick and cost-effective imaging of the shallow subsurface with acceptable resolution [9]. Some uses of this method in groundwater are determination of the thickness, boundary, 
and depth of different layers of an aquifer [10-13]. Due to the successful application of geoelectrical resistivity and GPR over the years in groundwater exploration, this propels me to adopt the method to investigate the underground seepage of hot water in the study area. Therefore, the main aim of this study is to investigate the subsurface structure and to delineate the underground seepage of hot water in Blawan geothermal field.

\section{Geological Setting}

Ijen caldera complex shaped elliptical caldera wall with diameter about $15-16 \mathrm{~km}$ which resulted from Kendeng volcano eruption. The eruption left only the northern caldera arch, while the southern caldera arch was covered by volcanic sediment [14].

In the past, there is Blawan Lake that existed in the caldera Ijen after caldera formed. The geological conditions in this region allow rain water trapped inside the caldera basin to accumulate and eventually formed a lake that is quite spacious with a diameter greater than $5 \mathrm{~km}$. The lake is in a fairly long period of time characterized by the thick presence of sedimentary clastic rocks near Banyu Pahit river, Sat Kali river, and Kali Sengon river [15].

The research area located in Blawan geothermal field, Bondowoso district, East Java, as shown in Figure 1. The hot springs distribution in Blawan geothermal field is shown in Figure 1. According to Sidarto, the hot springs flow in Blawan geothermal field in two different rock types, namely, Old Ijen volcanic rocks (Qpvi) and Young Ijen volcanic rock (Qhvi) [16]. The hot springs manifestations are clustered based on the discharge location of hot water [17].

\section{Materials and Methods}

The data acquisition strategy was to select acquisition site very close to hot water distribution (Figure 1), obtain typical resistivity evidence, and situate additional possible sites with similar morphological expression but unknown features. The entire measurement was carried out along the possible sites in the study area. To get good coupling between electrodes and ground, we scatter some water to ensure a wet surface condition. Based on hot spring distributions and possible location, we have determined 9 locations for geoelectrical resistivity and GPR field data acquisition (Figure 1).

3.1. Geoelectric Resistivity. Geoelectrical resistivity field data are acquired by dipole-dipole configuration using $\mathrm{Mac}-\mathrm{Ohm}$, OYO Japan Resistivity meters. The data was collected at various selected sites, namely, PB1, PB2, PB3, PB4, PB5, PB6, PB7, PB8, and PB9. Geoelectrical resistivity methods consist in a ground injection of an electrical current between two electrodes then measuring the induced potential difference between two potential electrodes $[18,19]$. The dipole-dipole is the most convenient configuration on the field especially for large spacing [16]. The dipole-dipole resistivity technique consists of a collinear array with current dipole separation of length $a$, potential dipole separation of length $a$, and a total distance between the dipoles of length na (Figure 2). The

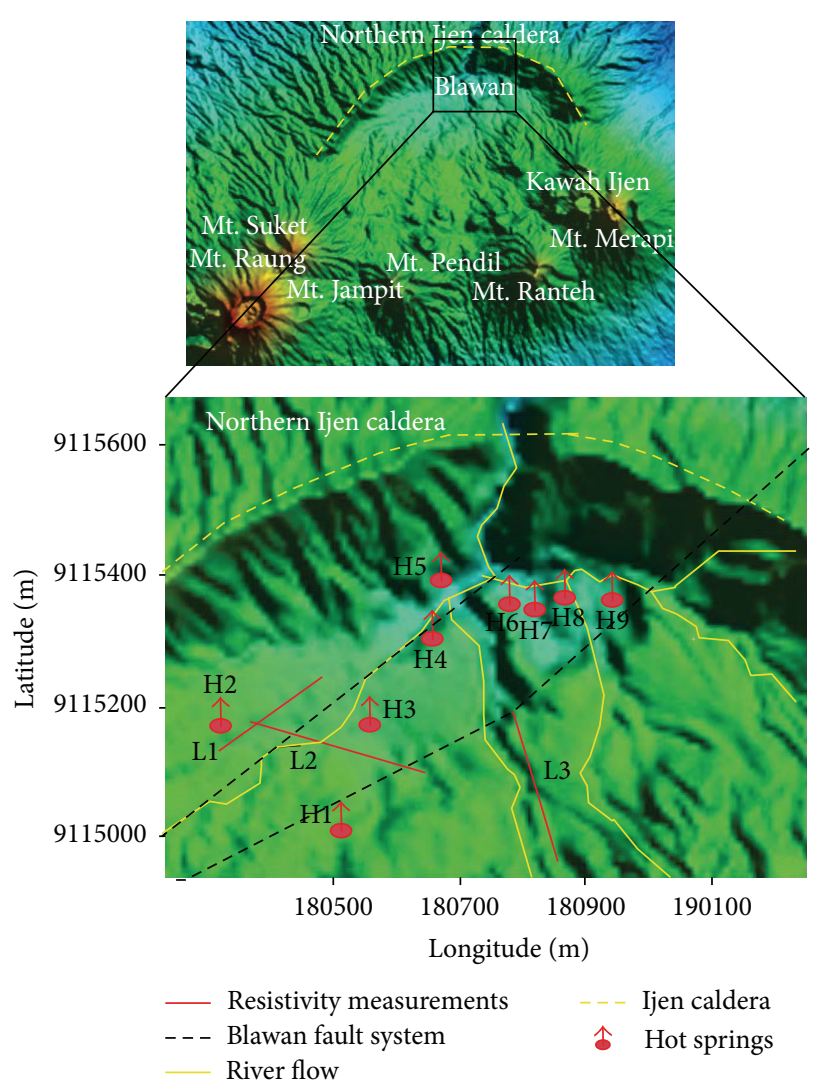

FIGURE 1: Research area.

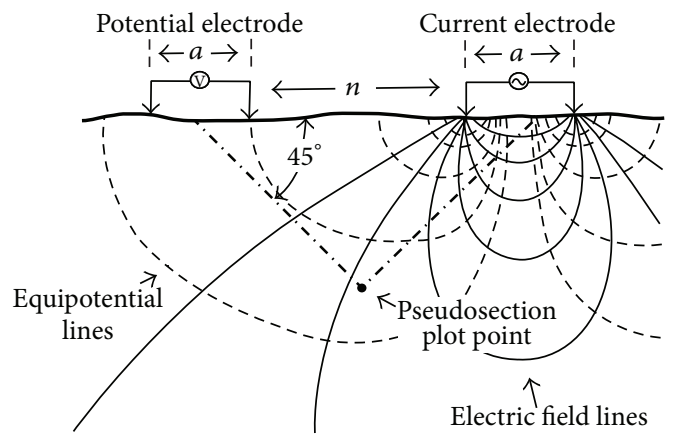

Figure 2: Dipole-dipole configuration [20].

current and potential electrodes are moved along a profile with constant spacing between electrodes. The apparent resistivity value is plotted along intersecting 45 -degree lines centered on the dipoles [20].

Generally the data obtained during geoelectric field measurements classically presented as apparent resistivity pseudosections, which give an approximate picture of the subsurface resistivity [9]. The apparent resistivity equation applied in data processing is

$$
\rho_{a}=\frac{V}{I} \operatorname{\pi an}(n+1)(n+2)=\frac{V}{I} K,
$$

where is $\rho_{a}$ apparent resistivity $(\Omega \mathrm{m}) ; V$ is voltage; $I$ is current; $a$ is electrode spacing; $n$ is datum point; $K$ is geometry factor. 
Geometry factor is very important to estimate the quality and quantity of resistivity data. The lower of a value will give decrease in $K$ value and resulted in high quality data. The longer line measurement makes $n$ value increase and then the $K$ value will increase and resulted in increasing the depth measurement.

The apparent resistivity value is the resistivity of a homogeneous ground which will give the same resistance value for the same electrode arrangement. The relationship between the apparent resistivity and the true resistivity is a complex relationship. To determine the true subsurface resistivity, an inversion of the measured apparent resistivity values using a computer program software package will be used [21].

The processing and modelling of geoelectrical data was done with RES2DINV which provides inverse pseudosections of resistivity and reflects the true resistivity of the study area $[18,22]$. It is a Windows based computer program that automatically determines a two-dimensional (2D) subsurface resistivity model for data obtained from electrical imaging surveys $[23,24]$. The inversion procedure using RES2DINV software is based on the regularized least-squares optimization method $[9,25]$. The conventional smoothnessconstrained least-squares method attempts to minimize the square of the changes in the model resistivity values and to smooth the boundaries. As a result, a model with a smooth variation in the resistivity values is obtained [26]. 2D resistivity images prospecting field information about both lateral and vertical distributions of the study area's resistivity can be used in both qualitative and quantitative ways for the identification of underground seepage of hot water at shallow depths.

\subsection{Ground Penetrating Radar (GPR). The GPR method is} based on transmitting a high frequency electromagnetic pulse (radio waves) from a transmitting antenna to the subsurface to probe lossy dielectric material and recording of the pulse responses reflected from the interfaces and objects below the subsurface $[27,28]$. GPR data are acquired using GPR Future 2005. Our GPR units consist of some components that are capable of being operated by a single user: the antenna, control unit, horizontal probe, USB Bluetooth dongle, PC to display, and external power supply (Figure 3). The Future 2005 is a multihead air coupled GPR instrument that comes packaged with a geophysical electromagnetic sensor (GEM). It has eight simultaneous sampling heads that cover an overlapping one-meter swath at the surface that provides multiple testing of anomalies. The radio wave produced is $450 \mathrm{MHz}$ [29]. Future 2005 and its accessories serve for analysis of detecting objects deposited and changes performed in the ground.

The data was taken at the same locations as the geoelectric resistivity sites, that is, at $\mathrm{PB} 1, \mathrm{~PB} 2, \mathrm{~PB} 3, \mathrm{~PB} 4, \mathrm{~PB} 5, \mathrm{~PB} 6, \mathrm{~PB} 7$, and PB8 location. Ground scan operating mode is used in this survey. This operating mode records a graphical measurement of the measured data. The device will send out the impulses and we have to walk continuously in the measure line. If all impulses of the first measured line were sent out, the device will stop automatically [30].

The registered data of the ground structure in real time will be transmitted and stored digitally to a PC for visual

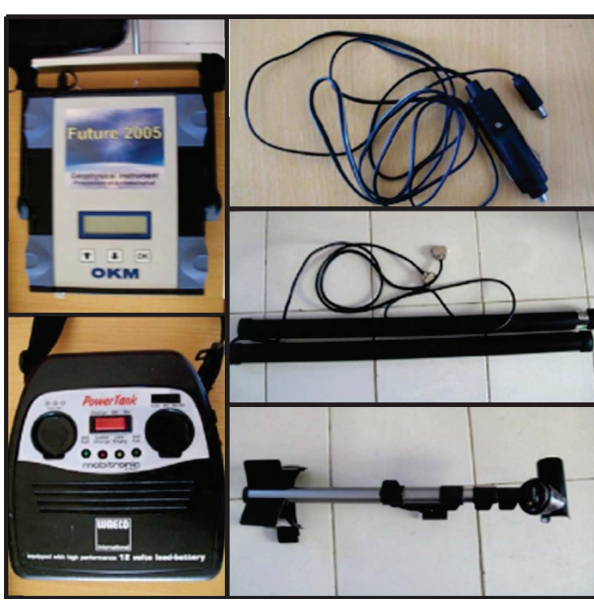

FIGURE 3: GPR Future 2005 set.

representation in a special software program. An anomaly is an area that has a sufficiently different wave signature to be identified as being separate from the background. Each anomaly detected below the surface reflects and inhibits the radio wave in unique ways [29]. The graphical representation should mainly include green, red, or blue color. The green color represents normal ground. Normally metallic objects are represented in red color and the blue color represents the cavities, water deposits, and diggings [30]. The focus of this study is on blue color which is considered as a hot water layer.

\section{Results and Discussion}

The data collected in the survey was interpreted by using RES2DINV 2D inversion software in which this software uses the rapid least-squares inversion method to model the final resistivity section [31]. The depth of the resistivity image depends on the distance between the electrodes, the used array, and the used equipment [32].

The $2 \mathrm{D}$ geoelectrical resistivity data have been processing and provide a description of rock layers with different resistivity values at each location. The $2 \mathrm{D}$ resistivity models at each location are grouped and shown in Figure 4.

Figure 4 shows the result resistivity data processing at 9 measurement locations. Sequentially, Figures 4(a), 4(b), 4(c), 4(d), 4(e), 4(f), 4(g), 4(h), and 4(i) are the result of resistivity data processing at locations PB1, PB2, PB3, PB4, PB5, PB6, PB7, PB8, and PB9. In Figure 3, low resistivity values $(<40 \Omega \mathrm{m})$ are dominant at locations PB2, PB5, PB6, and PB9. At locations PB1, PB3, and PB4, low resistivity values are also shown $(<40 \Omega \mathrm{m})$, but not as much as the previous location. At locations PB7 and PB8, despite low resistivity values, in those locations there is no manifestation of hot springs.

At location PB1, there are 3 resistivity and GPR lines in the same location, namely, PB1A (Figure 5(a)), PB1B (Figure 5(b)), and PB1C (Figure 5(c)). Figure 5 shows the data of geoelectric resistivity and GPR on PB1; GPR results are shown in the horizontal direction, while the results of geoelectric 


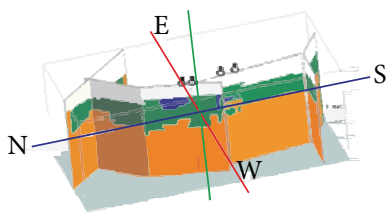

Low resistivity $\left(<40^{\prime} \Omega \cdot \mathrm{m}\right)$
Medium resistivity $\left(40-1280^{\prime} \Omega \cdot \mathrm{m}\right)$
High resistivity $\left(>1280^{\prime} \Omega \cdot \mathrm{m}\right)$
$\square$ Surface
8. Hot springs

(a)

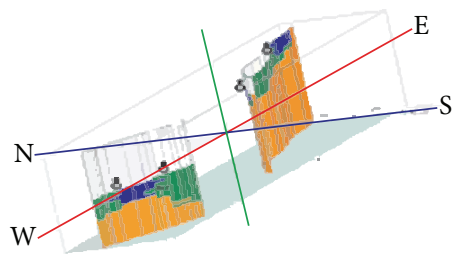

Low resistivity $\left(<40^{\prime} \Omega \cdot \mathrm{m}\right)$

Medium resistivity $\left(40-1280^{\prime} \Omega \cdot \mathrm{m}\right)$

High resistivity $\left(>1280^{\prime} \Omega \cdot \mathrm{m}\right)$

$\square$ Surface

3. Hot springs

(d)

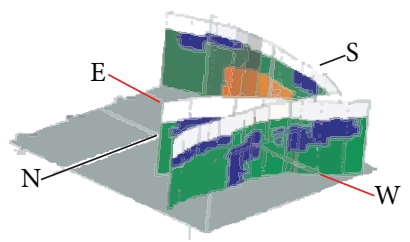

Low resistivity $\left(<40^{\prime} \Omega \cdot \mathrm{m}\right)$

Medium resistivity $\left(40-1280^{\prime} \Omega \cdot \mathrm{m}\right)$

High resistivity $(>1280 ' \Omega \cdot \mathrm{m})$

$\square$ Surface

d. Hot springs

(g)

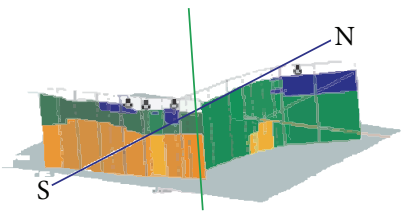

Low resistivity $\left(<40^{\prime} \Omega \cdot \mathrm{m}\right)$

Medium resistivity $\left(40-12800^{\prime} \Omega \cdot \mathrm{m}\right)$

High resistivity $\left(>1280^{\prime} \Omega \cdot \mathrm{m}\right)$

Surface

d. Hot springs

(b)

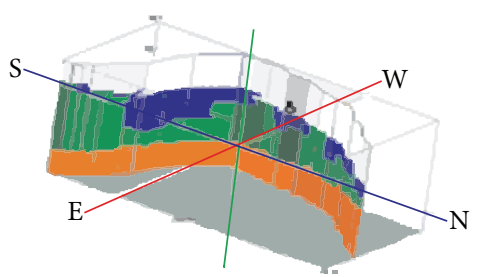

Low resistivity $\left(<40^{\prime} \Omega \cdot \mathrm{m}\right)$
Medium resistivity $\left(40-1280^{\prime} \Omega \cdot \mathrm{m}\right)$
High resistivity $\left(>1280^{\prime} \Omega \cdot \mathrm{m}\right)$
$\square$ Surface
6. Hot springs

(e)

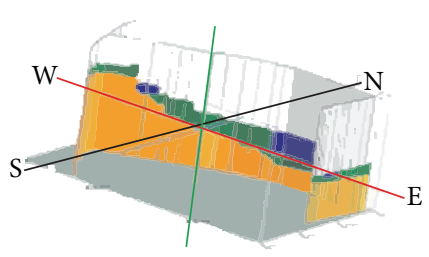

Low resistivity $\left(<40^{\prime} \Omega \cdot \mathrm{m}\right)$
Medium resistivity $\left(40-1280^{\prime} \Omega \cdot \mathrm{m}\right)$
High resistivity $\left(>1280^{\prime} \Omega \cdot \mathrm{m}\right)$
$\square$ Surface
8. Hot springs

(h)

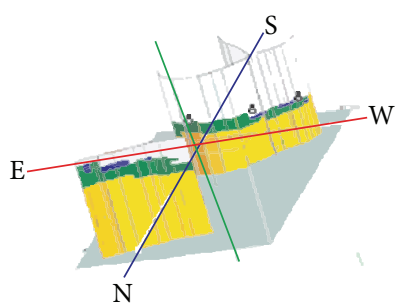

Low resistivity $\left(<40^{\prime} \Omega \cdot \mathrm{m}\right)$

Medium resistivity $\left(40-1280{ }^{\prime} \Omega \cdot \mathrm{m}\right)$

High resistivity $\left(>1280^{\prime} \Omega \cdot \mathrm{m}\right)$

Surface

d. Hot springs

(c)

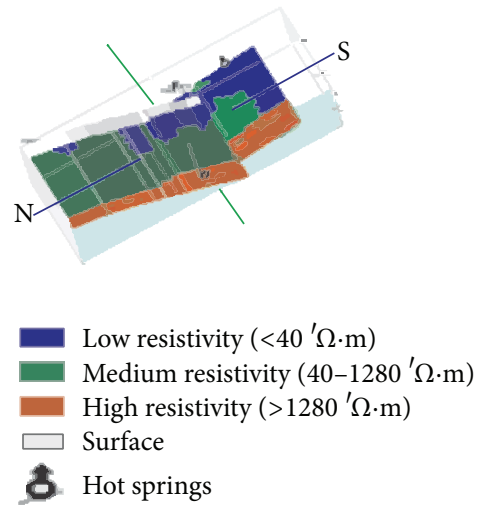

(f)
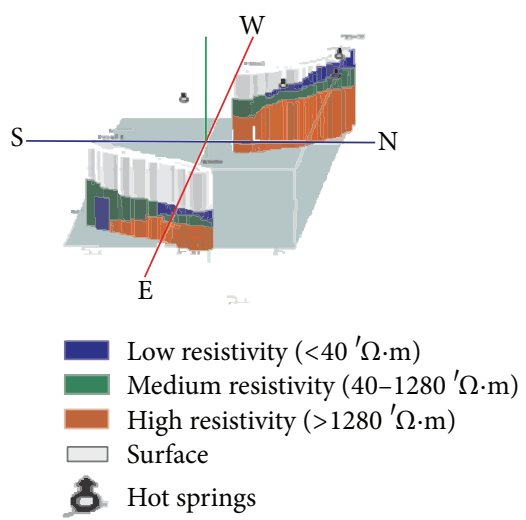

(i)

FIGURE 4: Result of resistivity data processing at 9 measurement locations in Blawan geothermal field.

resistivity are shown in the vertical direction. The total anomaly length of geoelectric resistivity is approximately $100 \mathrm{~m}$ and the depth range of the anomalies seems to be more than $25 \mathrm{~m}$. Based on the results of geoelectrical data, processing can be interpreted that the subsurface conditions at the location of PB1 are composed of a layer of silty sandstone that contains a lot of water indicated by the green layer $(40-1280 \Omega \mathrm{m})$ and lava rock represented by orange layer $(>1280 \Omega \mathrm{m})$, and the blue layer $(<40 \Omega \mathrm{m})$ indicates a layer that contains hot water. Figure 5 shows that the rock layers that contain hot water only present in PB1B (Figure 5(b)) at the horizontal profile of $55 \mathrm{~m}-60 \mathrm{~m}$ and extend down up to $5 \mathrm{~m}$ of depth under the surface, also at the horizontal profile of $75 \mathrm{~m}-80 \mathrm{~m}$, and extend down up to $10 \mathrm{~m}$ of depth under the surface. In PB1C line (Figure 5(c)), there is also the rock layer containing hot water which is present at the horizontal profile of $20 \mathrm{~m}-25 \mathrm{~m}$ and reaches the depth of $5 \mathrm{~m}$ under the surface.

Meanwhile, GPR processing results show the ground scan of PB1 location with an estimated maximum depth until $5 \mathrm{~m}$ under the surface. The PB1 is dominated by green and blue 

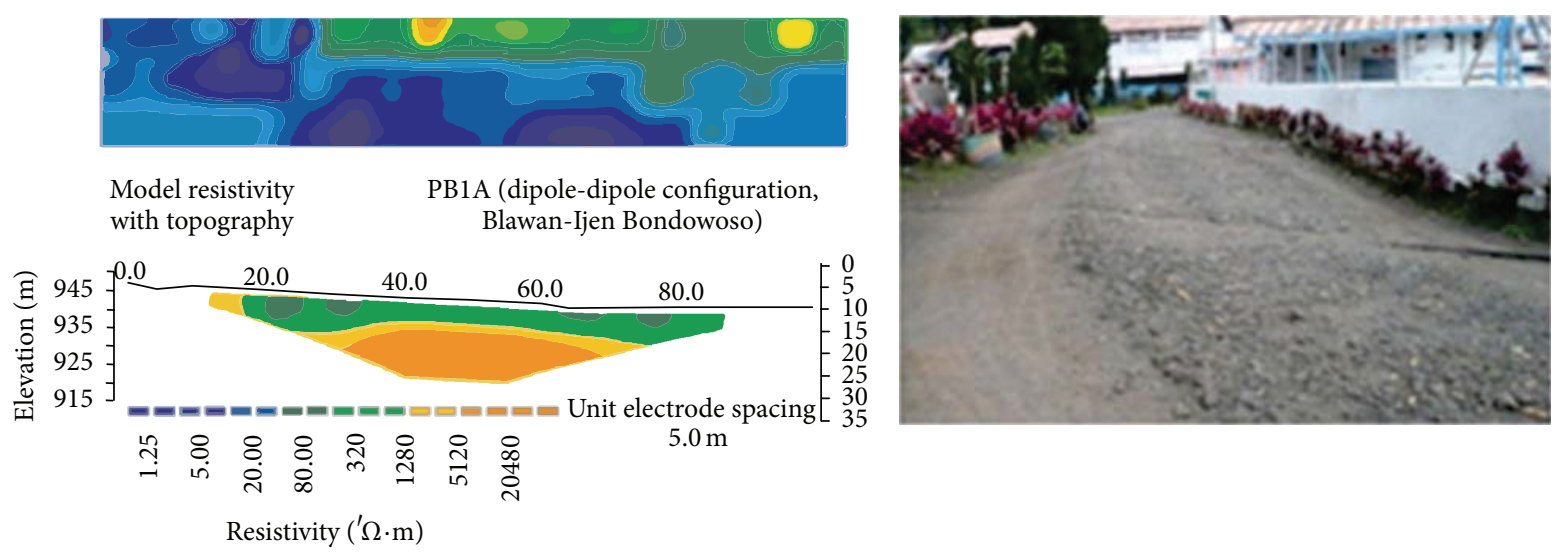

(a)
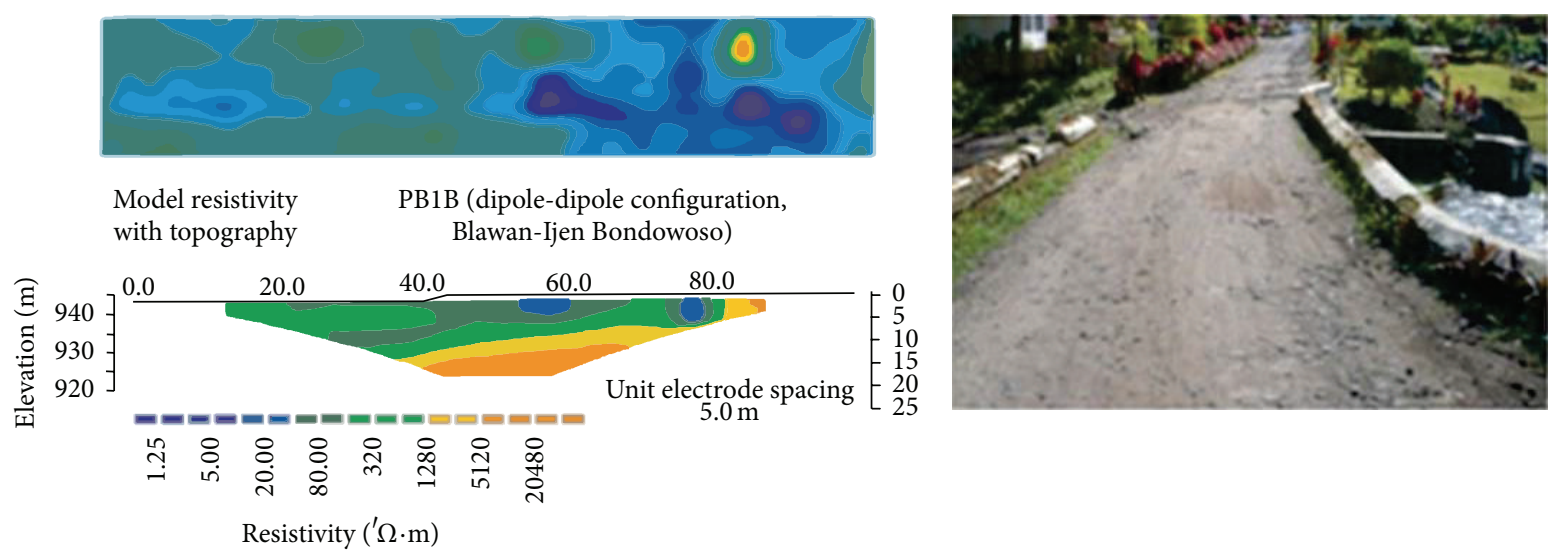

(b)

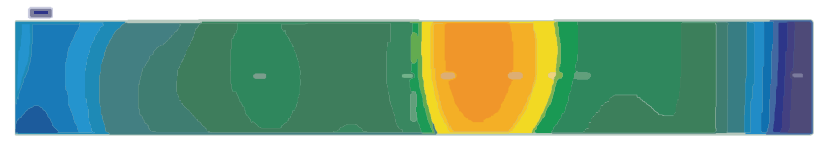

Model resistivity $\quad$ PB1C (dipole-dipole configuration, with topography Blawan-Ijen Bondowoso)
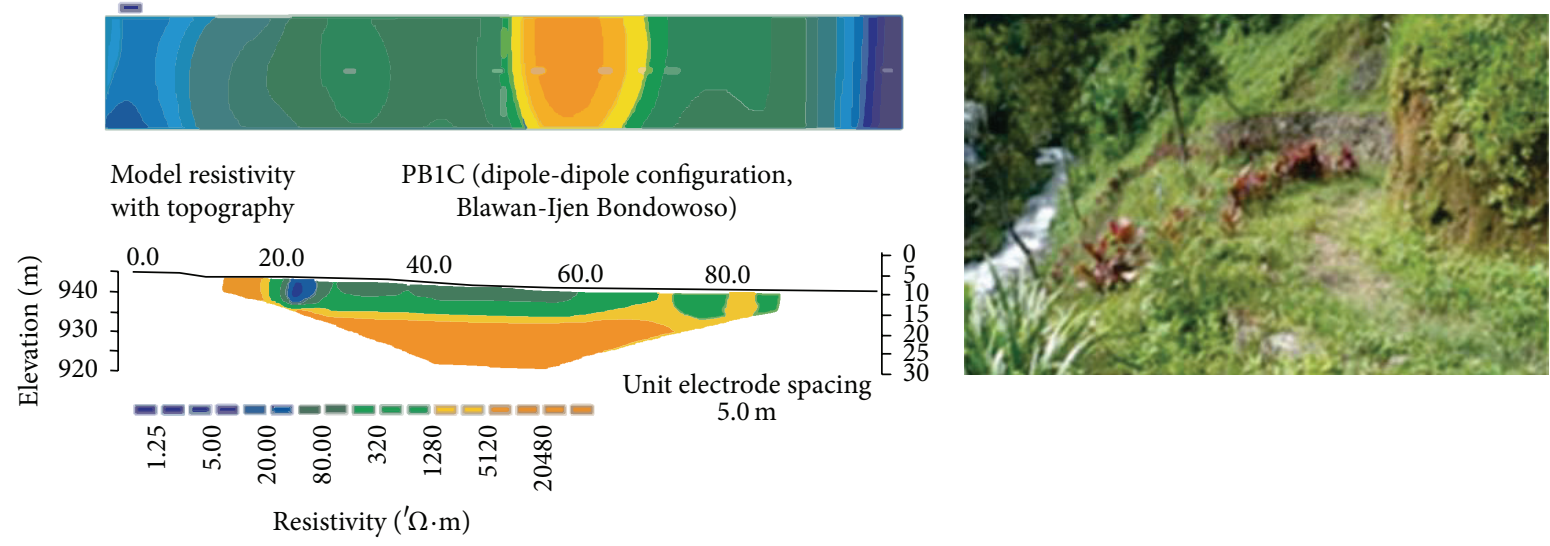

(c)

Figure 5: 2D Resistivity Mapping and GPR amplitude slice in locations (a) PB1A, (b) PB1B, and (c) PB1C.

layers that represent the layers of rock containing water. Conditions at the site showed that at PB1 there is a river flow in accordance with the GPR results. Yellow to orange layer from GPR processing results is a layer of dry solid and indicated by the presence of hills.

Location PB2 consists of 2 resistivity lines, namely, PB2A (Figure 6(a)) and PB2B (Figure 6(b)), and a line of GPR in the same direction with PB2B (Figure 6(b)). The total anomaly length of geoelectric resistivity results is approximately $100 \mathrm{~m}$ and the depth range of the anomalies reaches up to $25 \mathrm{~m}$. Based on the results of data processing geoelectric resistivity in Figure 6, it can be interpreted that the blue layer $(<40 \Omega \mathrm{m})$ is a type of rock layers that contain hot water. The results of resistivity data processing are supported by the presence of hot springs on the location. In fact, PB2A line contained hot water layer parallel to 3 hot springs; they are present 


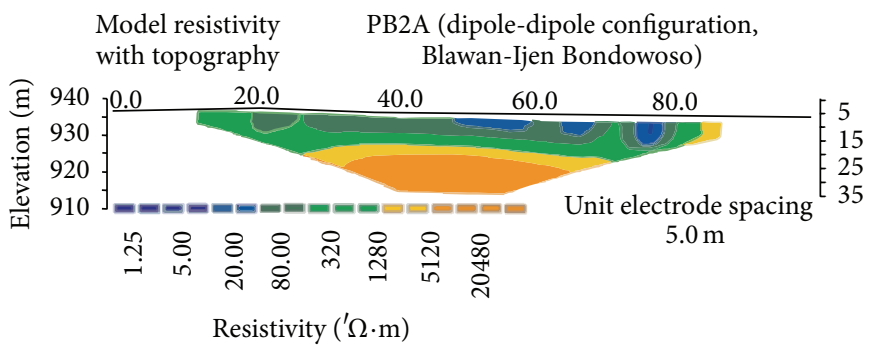

(a)
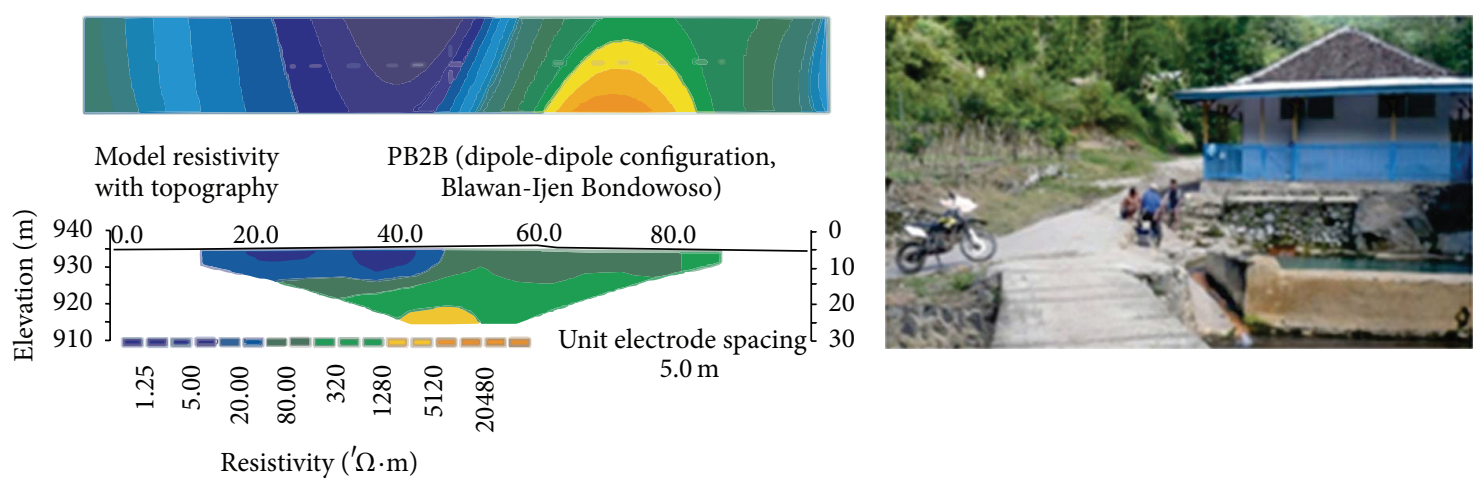

Horizontal scale is 64.25 pixels per unit spacing

Vertical exaggeration in model section $=0.52$

First electrode is located at $0.0 \mathrm{~m}$

Last electrode is located at $100.0 \mathrm{~m}$

(b)

FIGURE 6: 2D Resistivity Mapping and GPR amplitude slice in locations (a) PB2A and (b) PB2B.

along $50 \mathrm{~m}-60 \mathrm{~m}$ and $65 \mathrm{~m}-70 \mathrm{~m}$ of horizontal profile with $5 \mathrm{~m}$ of depth under the surface and also along $50 \mathrm{~m}-60 \mathrm{~m}$ and $75 \mathrm{~m}-80 \mathrm{~m}$ of horizontal profile with $10 \mathrm{~m}$ of depth under the surface. However, the hot water in PB2B line is parallel to 1 hot spring, along $12 \mathrm{~m}-48 \mathrm{~m}$ horizontal profile, and reaches up to $15 \mathrm{~m}$ of depth under the surface. There is also a silty sandstone layer that contains a lot of water which is indicated by the green layer (40-1280 $\Omega \mathrm{m})$. In addition, the deeper subsurface is estimated consisting of lava rocks indicated by the orange layer $(>1280 \Omega \mathrm{m})$.

As supporting data, we used the GPR method taken in the same location with PB2B line. GPR results show the ground scan of PB2 location with an estimated maximum depth until $5 \mathrm{~m}$ under the surface. Green and blue layers in GPR results indicate a layer containing water at PB2 location. These results are in accordance with the conditions on the survey area which indicates the flow of the river. The presence of hot springs, indicated by the blue layer, is found in the GPR result. Meanwhile, orange layer on the results of the GPR is a representation of nonaqueous layer.

PB3 site consists of 4 resistivity lines, namely, PB3A (Figure 7(a)), PB3B (Figure 7(b)), PB3C (Figure 7(c)), and PB3D (Figure $7(d)$ ). The result of resistivity data processing in Figure 7 shows that the subsurface at location PB3 is composed of hot water layer which is indicated by the blue layer $(<40 \Omega \mathrm{m})$. In PB3A line, the hot water layer is present along $11 \mathrm{~m}-12.5 \mathrm{~m}, 27 \mathrm{~m}-30 \mathrm{~m}, 32 \mathrm{~m}-35 \mathrm{~m}$, and $38 \mathrm{~m}-39 \mathrm{~m}$ of horizontal profile with $3 \mathrm{~m}$ of thickness. In PB3B line, the hot water layer is present along $22 \mathrm{~m}-23 \mathrm{~m}, 32 \mathrm{~m}-35 \mathrm{~m}$, and $76 \mathrm{~m}-79 \mathrm{~m}$ of horizontal profile with $5 \mathrm{~m}$ of thickness. The presence of hot water layer in Figure $7(\mathrm{~b})$ is supported by hot springs located in PB3A. The green layer $(40-1280 \Omega \mathrm{m})$ is a representation of sand that fills with water. In PB3D line, the hot water layer is present along $40 \mathrm{~m}-43 \mathrm{~m}$ of horizontal profile with $2.5 \mathrm{~m}$ of thickness and also along $55 \mathrm{~m}-65 \mathrm{~m}$ and $71 \mathrm{~m}-83 \mathrm{~m}$ of horizontal profile with $12.5 \mathrm{~m}$ of thickness. Overall, silty sandstone layers $(40-1280 \Omega \mathrm{m})$ contained water presence in all geoelectric resistivity line. Orange layer $(>1280 \Omega \mathrm{m})$ is a representation of lava rock present in all lines with a varied depth.

As supporting data, GPR data are taken exactly at the PB3A location (Figure 7(a)). GPR results show the ground scan of PB3 location with an estimated maximum depth until $5 \mathrm{~m}$ under the surface. Green and blue layers in GPR results indicate a layer containing water at PB3 location. GPR processing results as shown in Figure 7(a) show the predominance of blue layer which means that there is a layer which contains a lot of water above the hot springs and supports the presence of hot water.

Location PB4 consists of 2 resistivity lines, namely, PB4A (Figure 8(a)) and PB4C (Figure 8(b)). PB4C line is located in a higher elevation than the PB4A line. Each line has the manifestation of hot springs around. The total anomaly length of geoelectric resistivity results is approximately $100 \mathrm{~m}$ and 


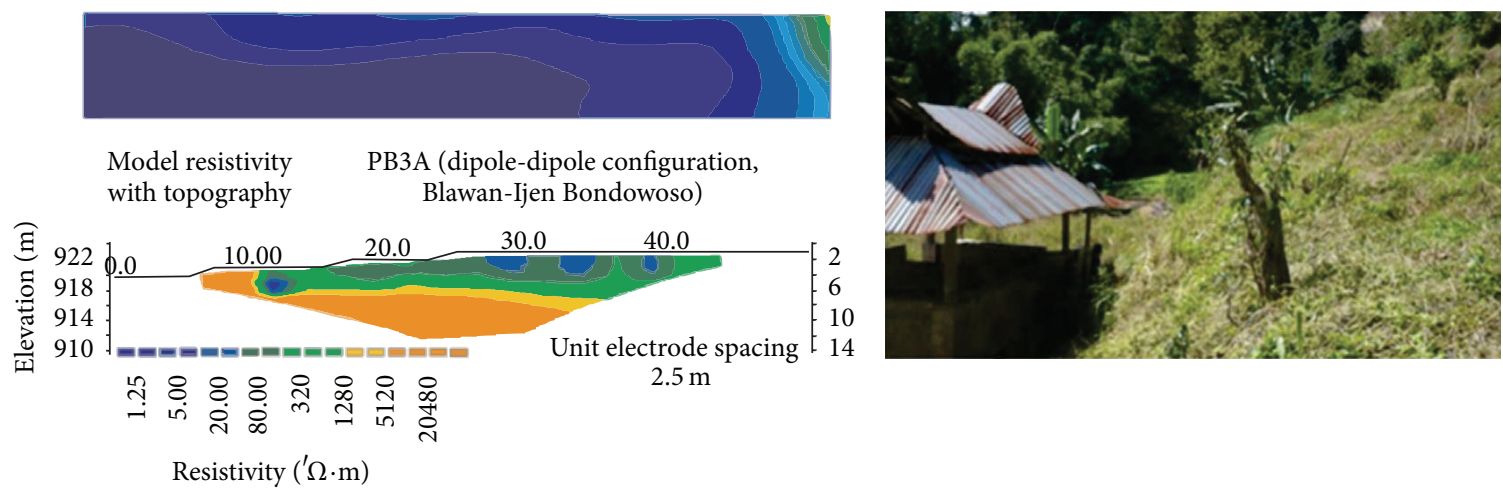

(a)

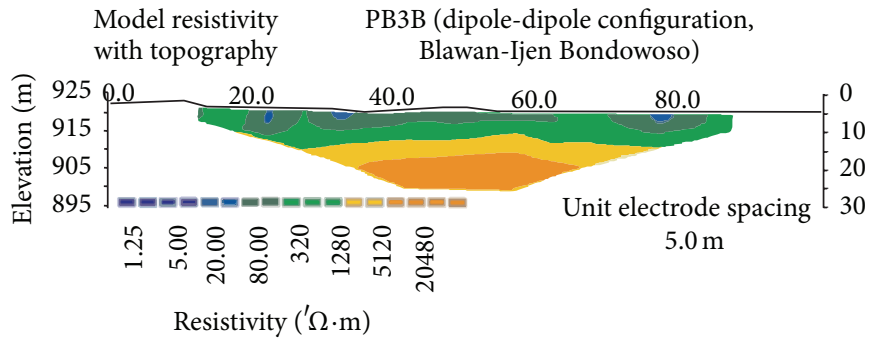

(b)

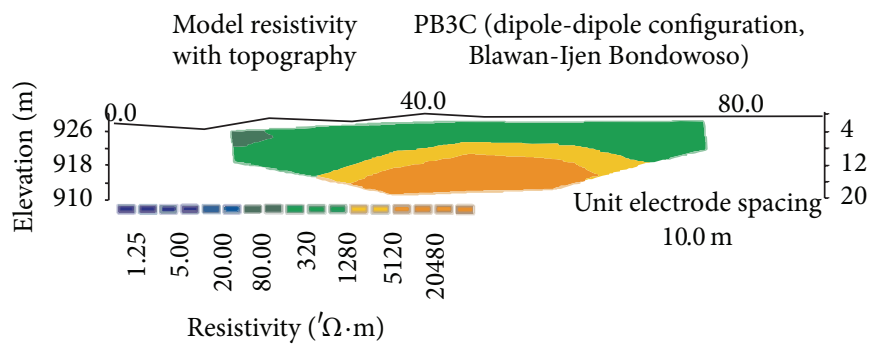

(c)

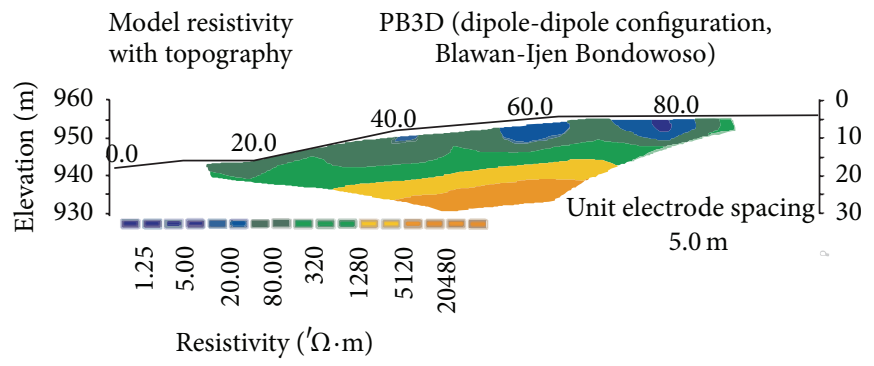

Horizontal scale is 64.25 pixels per unit spacing

Vertical exaggeration in model section $=0.52$

First electrode is located at $0.0 \mathrm{~m}$

Last electrode is located at $100.0 \mathrm{~m}$

(d)

Figure 7: 2D Resistivity Mapping and GPR amplitude slice in locations (a) PB3A, (b) PB3B, (c) PB3C, and (d) PB3D.

$150 \mathrm{~m}$ and the depth range of the anomalies reaches up to $25 \mathrm{~m}$. The hot water flow shown in blue layer $(<40 \Omega \mathrm{m})$ in PB4A line (Figure $8(\mathrm{a})$ ) is present along $21 \mathrm{~m}-22 \mathrm{~m}$ of horizontal profile and extends down up to $5 \mathrm{~m}$ of depth under the surface. While, in PB4C line (Figure 8(b)), the hot water is present along $22 \mathrm{~m}-24 \mathrm{~m}, 32 \mathrm{~m}-34 \mathrm{~m}, 115 \mathrm{~m}-120 \mathrm{~m}$, and
$126 \mathrm{~m}-127 \mathrm{~m}$ of horizontal profile with $7.5 \mathrm{~m}$ of thickness, in PB4C line, its subsurface is formed by a layer which is interpreted as the presence of limestone and allows the flow of hot water in the rocks crack. PB4C line taken in Damarwulan and adjacent to the limestone cave was once at the deepest part of Blawan Lake. 

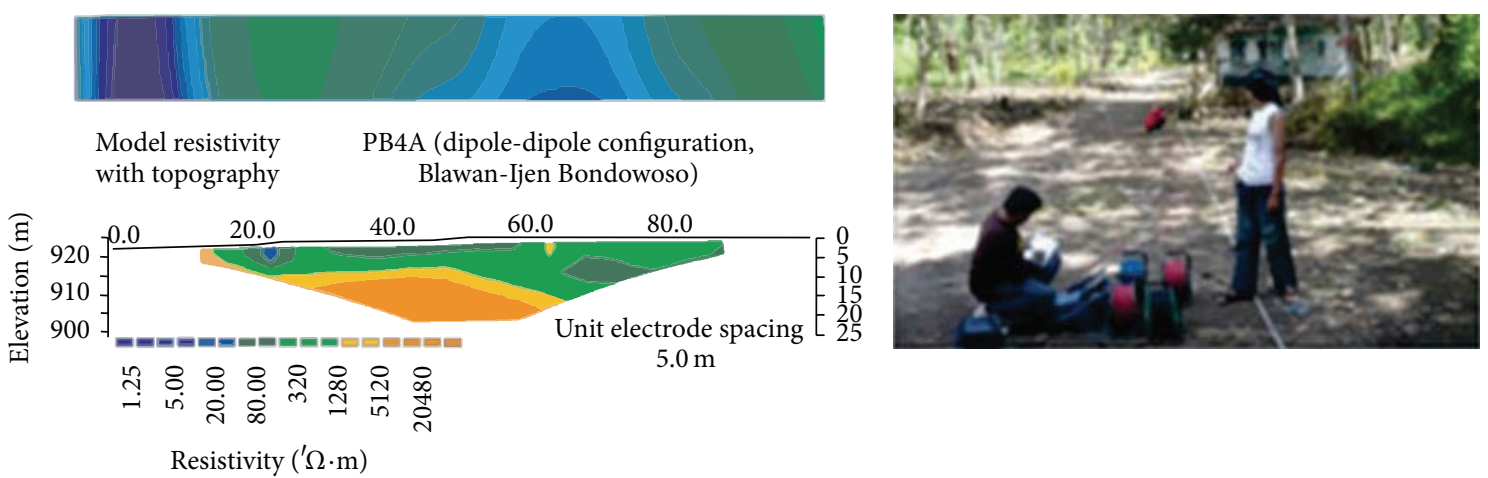

(a)

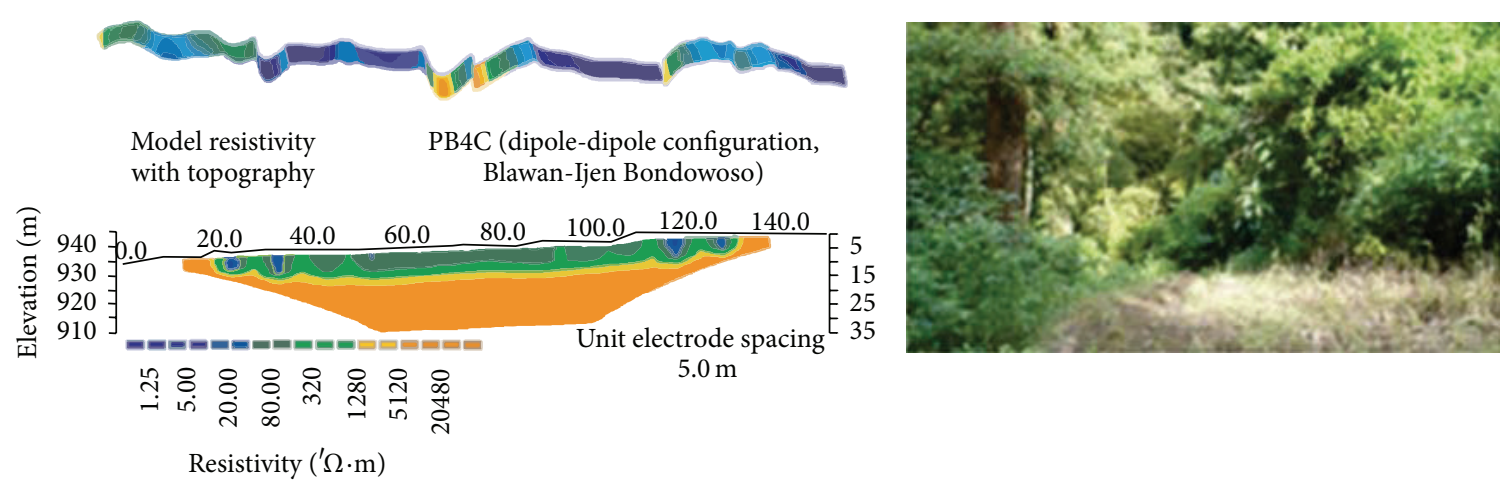

Horizontal scale is 42.83 pixels per unit spacing

Vertical exaggeration in model section $=0.59$

First electrode is located at $0.0 \mathrm{~m}$

Last electrode is located at $150.0 \mathrm{~m}$

(b)

Figure 8: 2D Resistivity Mapping and GPR amplitude slice in locations (a) PB4A and (b) PB4C.

As geoelectric resistivity supporting data, GPR method is used in the same location with resistivity. GPR results show the ground scan of PB4 location with an estimated maximum depth until $5 \mathrm{~m}$ under the surface. Green and blue layers in GPR results indicate a layer containing water at PB4 location. Interpretation of the dominance blue and green layers in Figures 8(a) and 8(b) shows a layer that contains a lot of water. Blue colors in GPR result match with those in resistivity result, which means there is a flow of hot water.

There are 2 resistivity lines in PB5, namely, PB5A and $\mathrm{PB} 5 \mathrm{~B}$. The total anomaly length of geoelectric resistivity is approximately $50 \mathrm{~m}$ and the depth range of the anomalies is up to $10 \mathrm{~m}$. Figure 9(a) is the result of PB5A data processing, and the blue layer $(<40 \Omega \mathrm{m})$ indicates the hot water presence along $9 \mathrm{~m}-15 \mathrm{~m}, 22 \mathrm{~m}-26 \mathrm{~m}, 29 \mathrm{~m}-34 \mathrm{~m}$, and $46 \mathrm{~m}-39 \mathrm{~m}$ of horizontal profile, close to the surface until $3 \mathrm{~m}$ of depth. The presence of hot water layer at PB5A is supported by the presence of the hot springs. PB5A line also consists of the aquifer layer $(40-1280 \Omega \mathrm{m})$ located above the lava rock layers $(>1280 \Omega \mathrm{m})$. Figure 9 (b) is the result of PB5B data processing showing the same result as the PB5A line. The hot water in PB5B line (Figure 9(b)) is present along $19 \mathrm{~m}-43 \mathrm{~m}$ of horizontal profile and reaches up to $6 \mathrm{~m}$ of depth from the surface. The elevation of PB5B line is higher than PB5A, so hot water is gathering towards PB5A as a lower location. Figure 9(b) also shows the result of GPR including the condition of the survey location. GPR results show the ground scan of PB5 location with an estimated maximum depth until $5 \mathrm{~m}$ under the surface. Green and blue layers in GPR results indicate a layer containing water at PB5 location. The results of GPR dominated with blue layer indicate a layer which contains hot water.

PB6 site consists of 2 resistivity lines, namely, PB6A and PB6B. Total depth generated by each line is different, $25 \mathrm{~m}$ for PB6A line and $14 \mathrm{~m}$ for PB6B line depending on the separation of the current and potential electrodes used in PB6A line $(100 \mathrm{~m})$ and PB6B line $(50 \mathrm{~m})$. The resistivity result of PB6A (Figure $10(\mathrm{a}))$ shows the hot water layer $(<40 \Omega \mathrm{m})$ presence along $13 \mathrm{~m}-41 \mathrm{~m}, 50 \mathrm{~m}-55 \mathrm{~m}$, and $75 \mathrm{~m}-79 \mathrm{~m}$ of horizontal profile and up to $15 \mathrm{~m}$ of depth under the surface. However, in PB6B (Figure 10(b)) the hot water layer almost covers all of horizontal profile and up to $9 \mathrm{~m}$ of depth under the surface. Besides that, the subsurface in PB6 is formed by silty sandstone layer $(40-1280 \Omega \mathrm{m})$ and lava rock layers $(>1280 \Omega \mathrm{m})$.

At PB6 there are 3 GPR lines, 2 of them taken in the same position with PB6A (Figure 10(a)) and PB6B (Figure 10(b)) and the third one located in the way towards hot springs (Figure 10(c)). The GPR results indicate the presence of the hot water flow support PB6A resistivity result. GPR results 


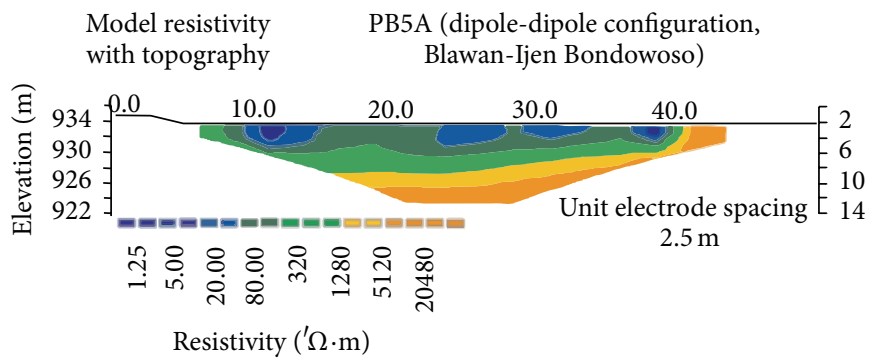

(a)

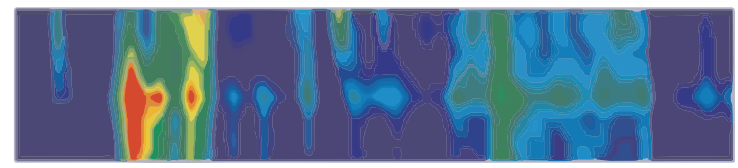

Model resistivity with topography

PB5B (dipole-dipole configuration, Blawan-Ijen Bondowoso)
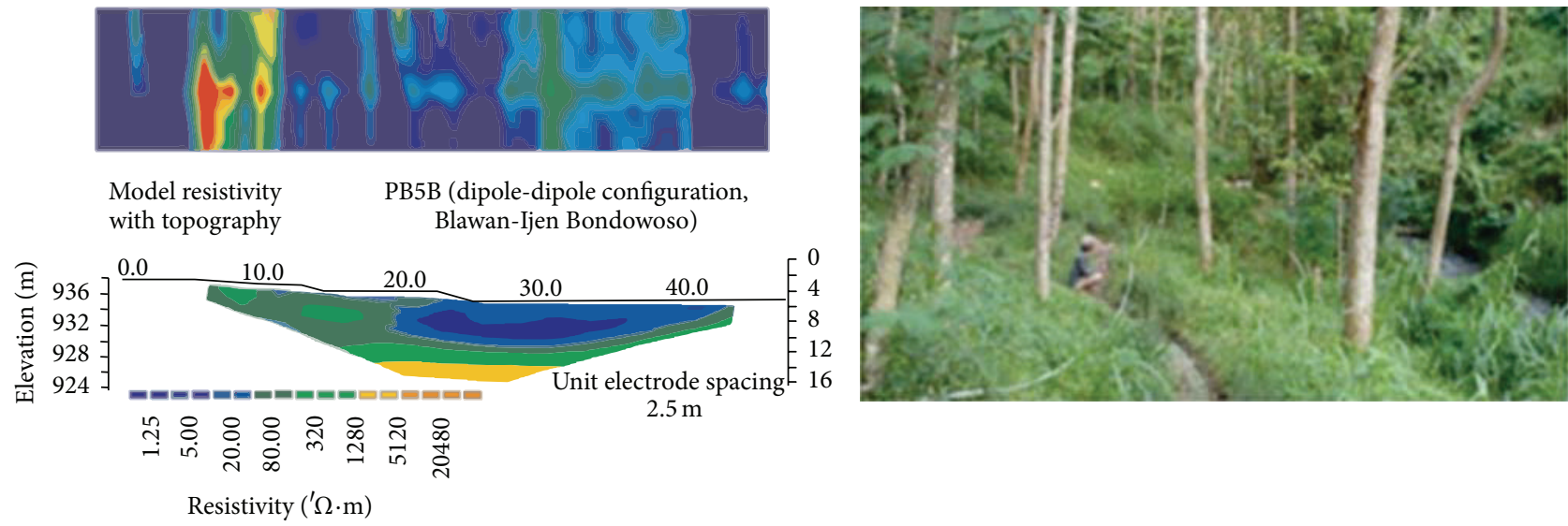

Horizontal scale is 63.76 pixels per unit spacing

Vertical exaggeration in model section $=0.54$

First electrode is located at $0.0 \mathrm{~m}$

Last electrode is located at $50.0 \mathrm{~m}$

(b)

FIgURE 9: 2D Resistivity Mapping and GPR amplitude slice in locations (a) PB5A and (b) PB5B.

show the ground scan of PB6 location with an estimated maximum depth until $5 \mathrm{~m}$ under the surface. Green and blue layers in GPR results indicate a layer containing water at PB6 location. The blue color in Figure 10(c) shows the presence of a hot spring.

At the location of $\mathrm{PB} 7$ site, there are 3 resistivity lines, namely, PB7A (Figure 11(a)), PB7B (Figure 11(b)), and PB7C (Figure 11(c)). The total anomaly length of geoelectric resistivity is approximately $100 \mathrm{~m}$ and the depth range of the anomalies is up to $25 \mathrm{~m}$. This region is dominant with groundwater recharge demonstrated by the construction citizen's water reservoir. In all of resistivity lines, it seems that there is hot water layer which is indicated by the blue layer $(<40 \Omega \mathrm{m})$. The resistivity result of PB7A (Figure 11(a)) shows the hot water layer $(<40 \Omega \mathrm{m})$ presence along $12 \mathrm{~m}-59 \mathrm{~m}$ of horizontal profile and spreads over from the surface up to $25 \mathrm{~m}$ of depth under the surface, also along $77 \mathrm{~m}-87 \mathrm{~m}$ of horizontal profile with $15 \mathrm{~m}$ of thickness. However, in PB7B (Figure 11(b)), the hot water layer almost covers all of horizontal profile and spreads over up to $20 \mathrm{~m}$ of depth under the surface. The hot water layer in PB7C (Figure 11(c)) is present along $20 \mathrm{~m}-26 \mathrm{~m}$ and $62 \mathrm{~m}-85 \mathrm{~m}$ of horizontal profile and extends down up to $7 \mathrm{~m}$ of depth under the surface. Overall, the subsurface in PB7 is formed by aquifer layer $(40-1280 \Omega \mathrm{m})$ as shown in
Figures 11(a) and 11(b) by the green layer. But Figure 11(c) has different characteristics; there is an intrusion lava rocks layer $(>1280 \Omega \mathrm{m})$ in PB7C line. The hot water coming from the hot water layer in PB7 will flow toward a lower place. This possibility is evidenced by the presence of hot springs in PB6 which has lower elevation than PB7.

As geoelectric resistivity supporting data, GPR method is used in the same location with resistivity line. GPR results show the ground scan of PB7 location with an estimated maximum depth until $5 \mathrm{~m}$ under the surface. Green and blue layers in GPR results indicate a layer containing water at PB7 location. GPR data interpretation on PB7 (Figure 11) shows the presence of potential hot water on this line. In accordance with the results of geoelectric resistivity, PB7A, PB7B, and PB7C are formed by aquifer layers.

At location PB8, there are 3 resistivity lines, namely, PB8A (Figure 12(a)), PB8B (Figure 12(b)), and PB8C (Figure 12(c)). The subsurface is dominated by a high resistivity rock $(>1280 \Omega \mathrm{m})$ shown in Figure 12. The presence of hot water layer $(<40 \Omega \mathrm{m})$ is less than the igneous layers $(>1280 \Omega \mathrm{m})$. In PB8B (Figure 12(b)), the hot water layer is present along $20 \mathrm{~m}-24 \mathrm{~m}$ and $77 \mathrm{~m}-84 \mathrm{~m}$ of horizontal profile with $5 \mathrm{~m}$ of thickness, while the hot water layer in PB8C (Figure 12(c)) is present along $10.5 \mathrm{~m}-12.5 \mathrm{~m}$ and $15 \mathrm{~m}-23 \mathrm{~m}$ of horizontal 

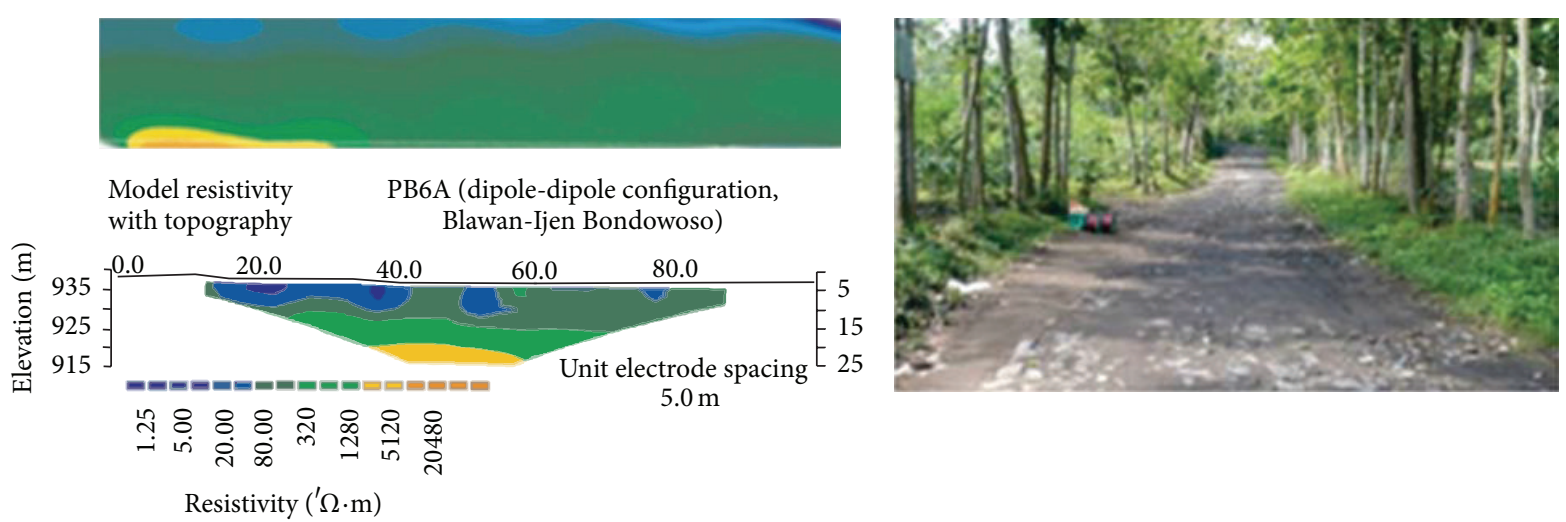

(a)

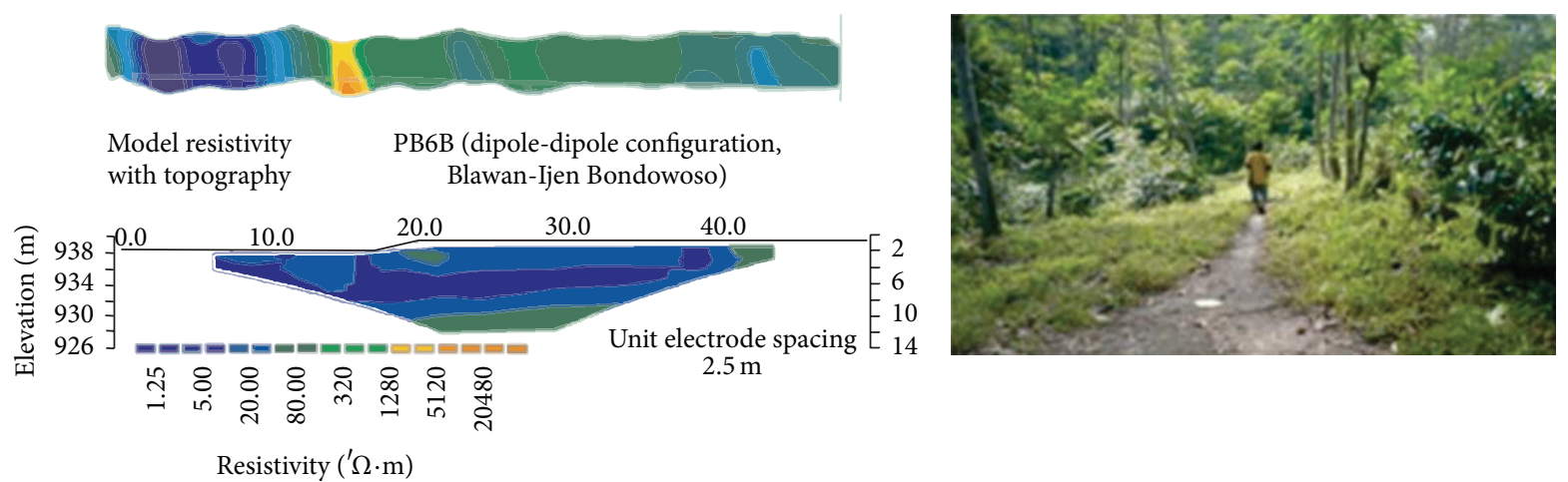

Horizontal scale is 42.83 pixels per unit spacing

Vertical exaggeration in model section $=0.59$

First electrode is located at $0.0 \mathrm{~m}$

Last electrode is located at $50.0 \mathrm{~m}$

(b)
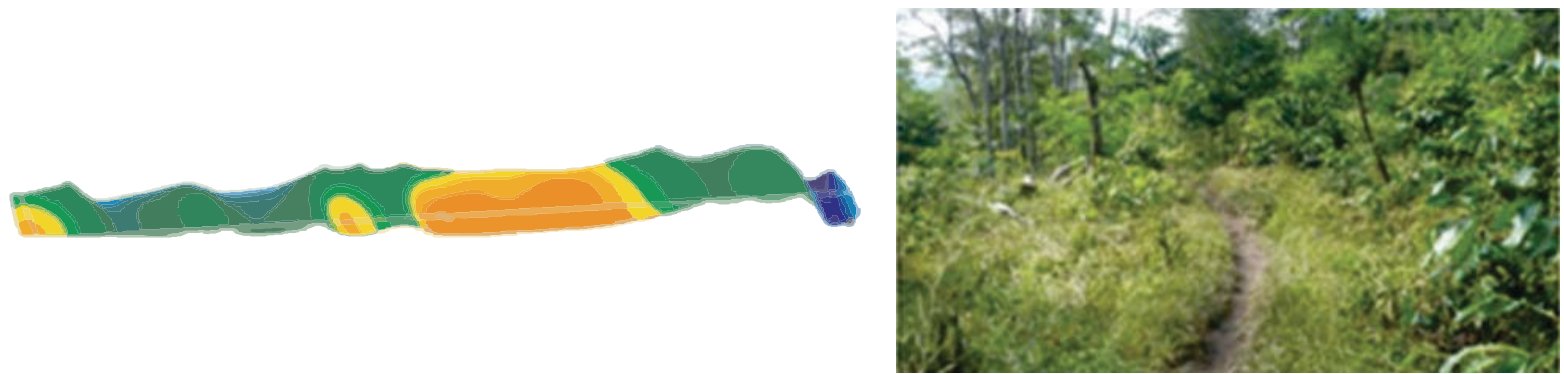

(c)

FIGURE 10: 2D Resistivity Mapping and GPR amplitude slice in locations (a) PB6A, (b) PB6B, and (c) PB6C.

profile with $3 \mathrm{~m}$ of thickness. It is estimated that the hot water is towards a lower place in PB4. This assumption is strengthened by the presence of hot spring in PB4.

As resistivity supporting data, GPR data are taken in all of resistivity lines. GPR results show the ground scan of PB8 location with an estimated maximum depth until $5 \mathrm{~m}$ under the surface. Green and blue layers in GPR results indicate a layer containing water at PB7 location. The GPR results in Figure 12 show the dominance of the aquifer layer there in all lines.
PB9 site consists of 2 resistivity lines, namely, PB9A and PB9B. The total anomaly length of geoelectric resistivity is approximately $50 \mathrm{~m}$ and the depth range of the anomalies is up to $12 \mathrm{~m}$. The subsurface in PB9A line (Figure 13(a)) shows the presence of low resistivity values $(<40 \Omega \mathrm{m})$ which is a representation of the hot water. There is a hot spring along PB9A line along $11 \mathrm{~m}-13 \mathrm{~m}$ of horizontal profile and it reaches up to $3 \mathrm{~m}$ of depth under the surface. The result of $\mathrm{PB} 9 \mathrm{~B}$ resistivity line (Figure 13(b)) shows that aquifer layer $(40-1280 \Omega \mathrm{m})$ and hot water layer $(<40 \Omega \mathrm{m})$ form near the surface with $3 \mathrm{~m}$ of 

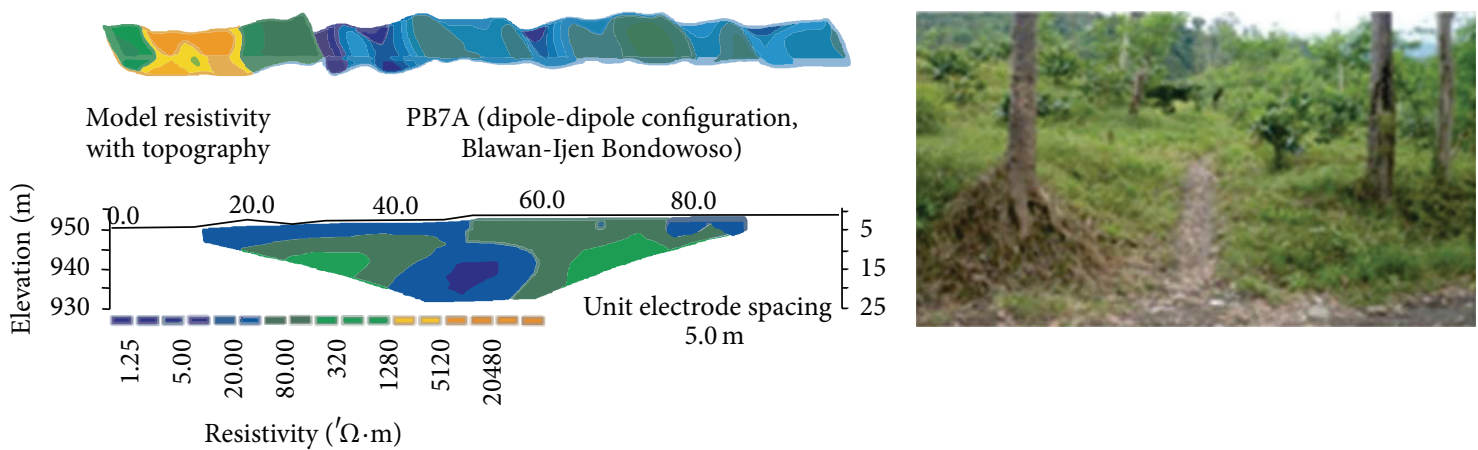

(a)
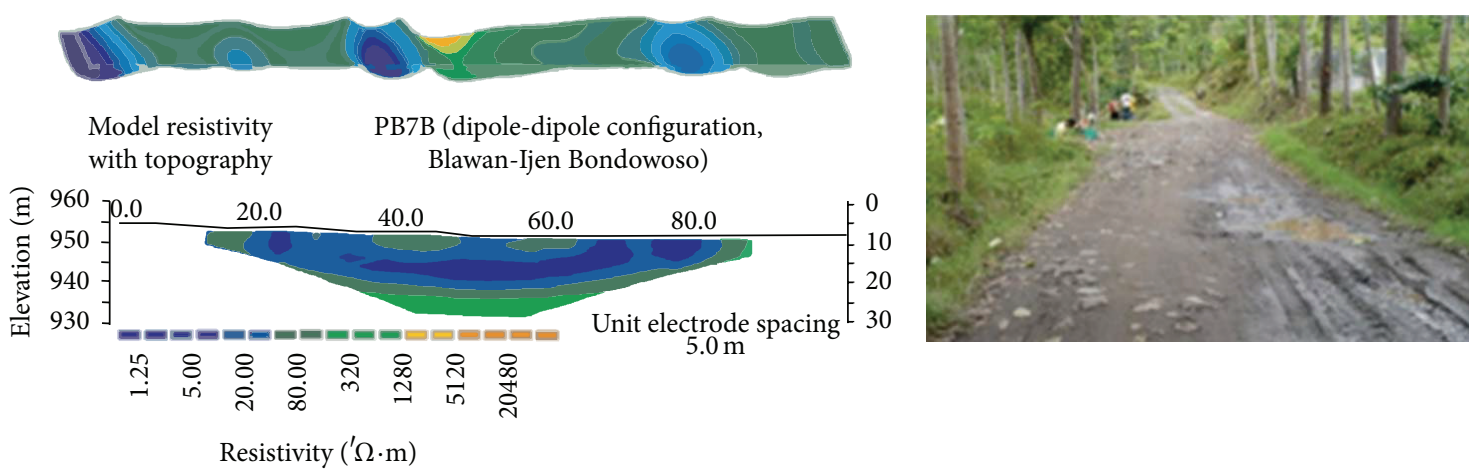

(b)
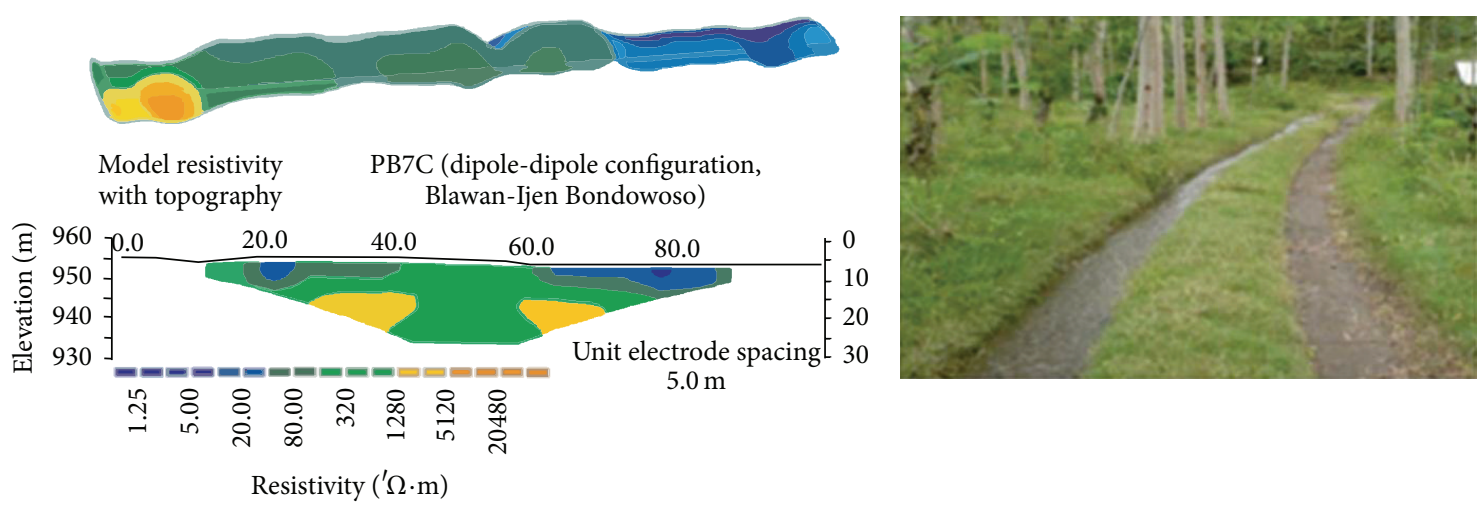

Horizontal scale is 64.25 pixels per unit spacing

Vertical exaggeration in model section $=0.52$

First electrode is located at $0.0 \mathrm{~m}$

Last electrode is located at $100.0 \mathrm{~m}$

(c)

Figure 11: 2D Resistivity Mapping and GPR amplitude slice in locations (a) PB7A, (b) PB7B, and (c) PB7C.

thickness. Meanwhile, the bottom layer of the subsurface is lava rock with high resistivity values $(>1280 \Omega \mathrm{m})$.

In Figure 14, the low resistivity values appear clumped and spread. Based on visual observations, the hot springs are distributed to the right and left of the hill and follow the river flow. In accordance with the characteristic of water that flows to a lower level, the underground seepage of hot water is towards the Northeast (Kendeng Caldera Arc) that has a lower topography with fault system and the presence of a waterfall.

\section{Conclusions}

In Blawan area, low resistivity values $(<40 \Omega \mathrm{m})$ are interpreted as a hot water layer. Furthermore, the resistivity values between 40 and $1280 \Omega \mathrm{m}$ are interpreted as aquifer layers and the high resistivity values $(>1280 \Omega \mathrm{m})$ are interpreted as lava rock. The underground seepage of hot water in Blawan geothermal field follows existing fault. Distribution of hot springs mostly to the Northeast follows the river flow pattern. Some hot springs located along the river showed that 

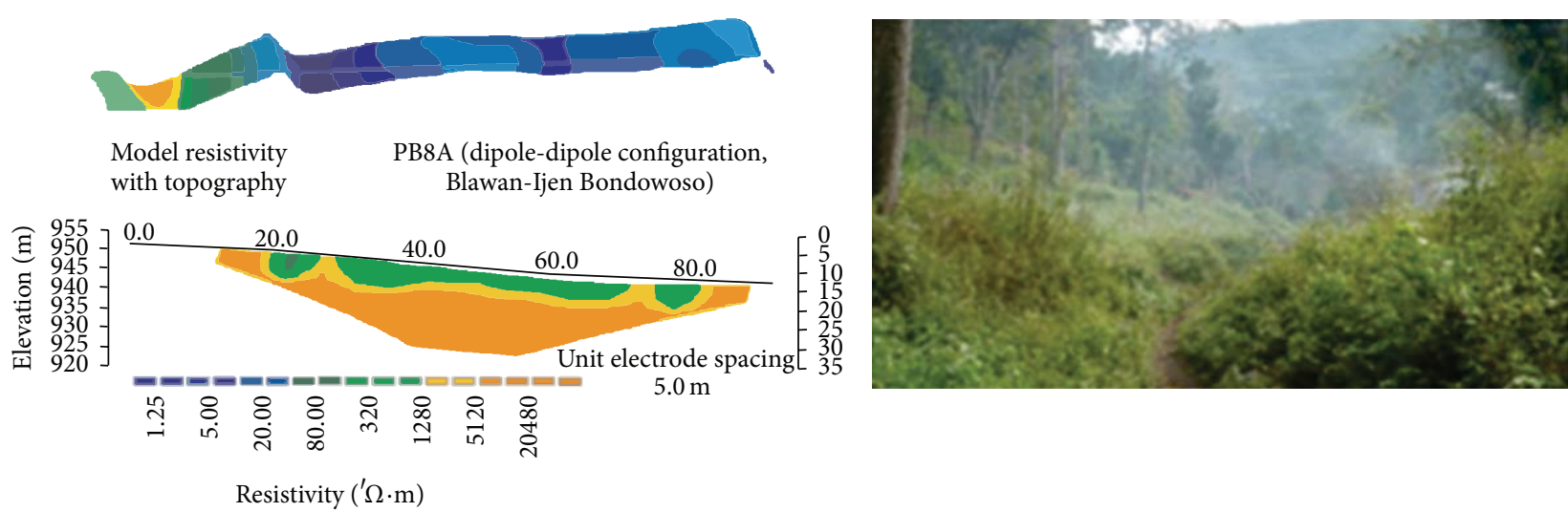

(a)

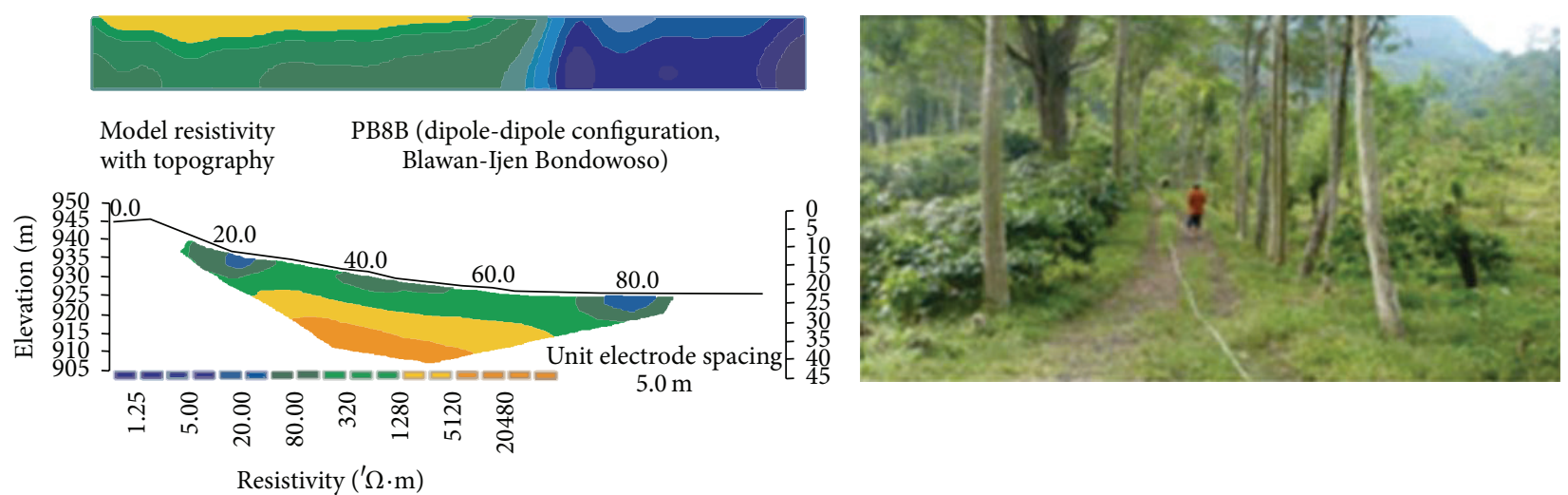

(b)

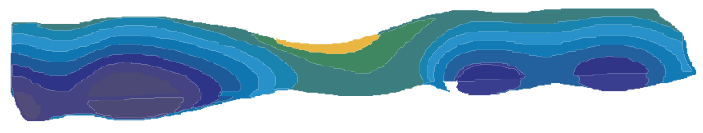

Model resistivity PB8C (dipole-dipole configuration, with topography Blawan-Ijen Bondowoso)
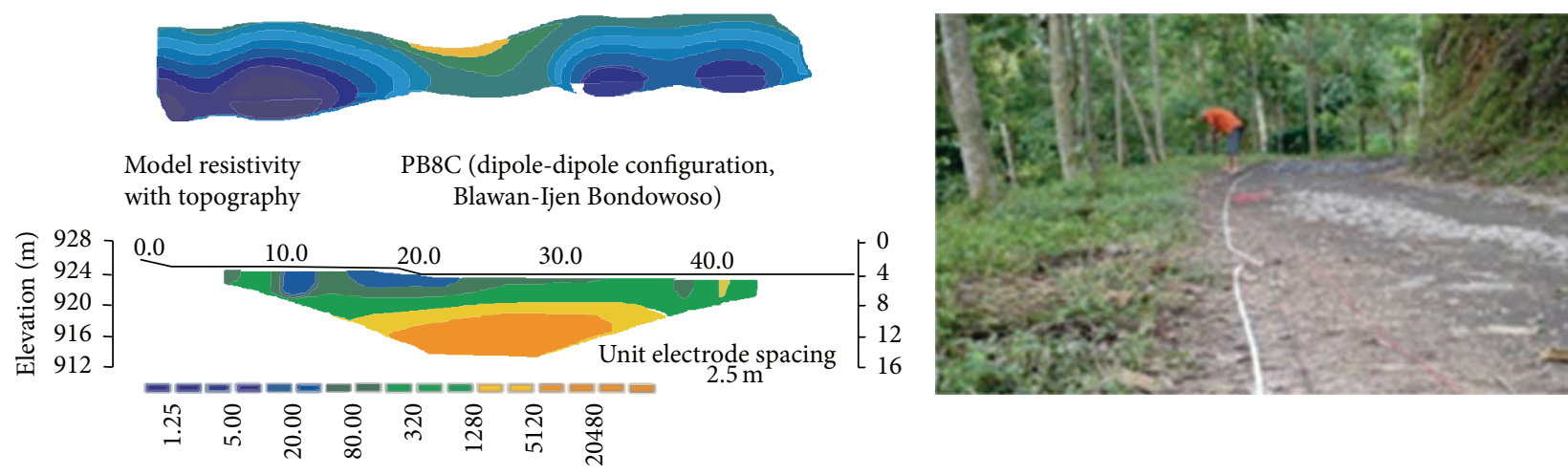

Resistivity $(' \Omega \cdot m)$

Horizontal scale is 63.70 pixels per unit spacing

Vertical exaggeration in model section $=0.54$

First electrode is located at $0.0 \mathrm{~m}$

Last electrode is located at $50.0 \mathrm{~m}$

(c)

FIGURE 12: 2D Resistivity Mapping and GPR amplitude slice in locations (a) PB8A, (b) PB8B, and (c) PB8C.

underground seepage of hot water is impermeable layer with a resistivity value less than $40 \Omega \mathrm{m}$.

\section{Competing Interests}

The authors declare that there are no competing interests regarding the publication of the paper.

\section{Acknowledgments}

Thanks are due to the Geophysical Laboratory of Physics, University of Brawijaya, and staff who helped in the study. Thanks are due to Blawan-Ijen Team from Indonesia Multimedia and all of friends for their help and cooperation during data acquisition. This study was partially funded by PUPT, PHK, and USAID. 


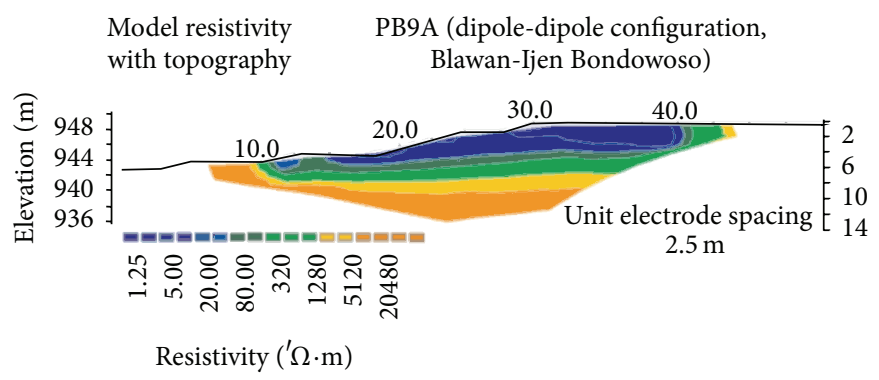

(a)

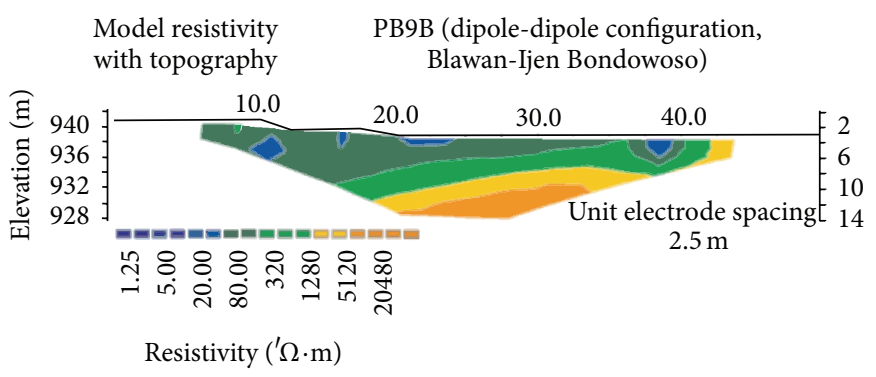

Horizontal scale is 63.70 pixels per unit spacing

Vertical exaggeration in model section $=0.50$

First electrode is located at $0.0 \mathrm{~m}$

Last electrode is located at $50.0 \mathrm{~m}$

(b)

FIgURE 13: 2D Resistivity Mapping and GPR amplitude slice in locations (a) PB9A and (b) PB9B.

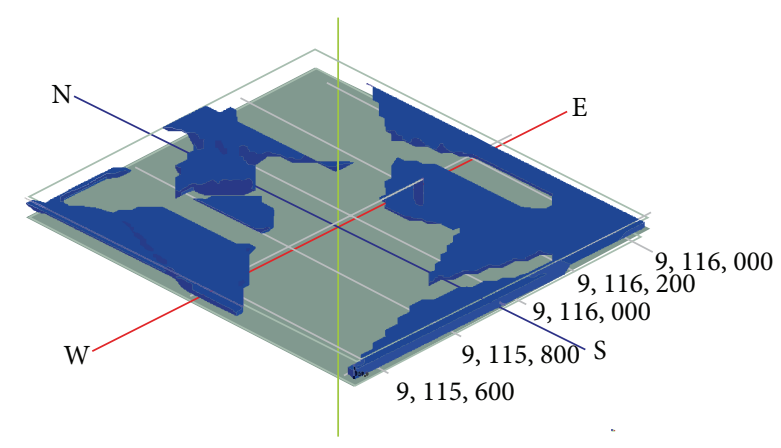

Figure 14: The underground seepage of hot water in Blawan geothermal field.

\section{References}

[1] Department of Energy and Mineral Resources, Geothermal Potential in East Java, 2012, http://esdm.jatimprov.go.id/esdm/ attachments/article/37/Data\%20Eka-potensi\%20panasbumi\%20jatim\%202012.pdf.

[2] A. Afandi, S. Maryanto, and A. Rachmansyah, "Identification reservoir geothermal based on geomagnetic method in area blawan sempol district bondowoso," Journal of Neutrino, vol. 6, no. 1, pp. 1-10, 2013.

[3] R. A. Raehanayati and S. Maryanto, "Study of Blawan-Ijen geothermal energy potential, East Java based on gravity method," J. Neutrino, vol. 6, no. 1, pp. 31-39, 2013.

[4] C. N. Dewi, S. Maryanto, and A. Rachmansyah, "Blawan geothermal system, East Java based on Magnetotelluric survey,"
Jurnal RISET Geologi dan Pertambangan, vol. 25, no. 2, p. 111, 2015.

[5] D. Santoso, Introduction to Geophysical Engineering, ITB Press, Bandung, Indonesia, 2002.

[6] P. Vingoe, Electrical Resistivity Surveying, Atlas Copco ABEM, Stockholm, Sweden, 1972.

[7] A. S. Ogungbe, J. A. Olowofela, O. O. Oresanya, and A. A. Alabi, "Mapping of unconfined aquifer using vertical electrical sounding (VES) at Lagos State University (Lasu), Ojo," Applied Science Research, vol. 2, no. 2, pp. 24-34, 2010.

[8] A. A. R. Zohdy, "A new method for differential resistivity sounding," Geophysics, vol. 34, no. 6, pp. 924-943, 1969.

[9] M. Metwaly and F. Alfouzan, "Application of 2-D geoelectrical resistivity tomography for subsurface cavity detection in the eastern part of Saudi Arabia," Geoscience Frontiers, vol. 4, no. 4, pp. 469-476, 2013.

[10] G. D. Khan, Waheedullah, and A. S. Bhatti, "Groundwater investigation by using resistivity survey in Peshawar, Pakistan," Journal of Resource Development and Management, vol. 2, pp. 9-20, 2013.

[11] A. A. R. Zohdy and D. B. Jackson, "Application of deep electrical soundings for groundwater exploration in Hawaii," Geophysics, vol. 34, no. 4, pp. 584-600, 1969.

[12] M. E. Young, R. G. M. De Bruijn, and A. Bin Salim Al-Ismaily, "Exploration of an alluvial aquifer in Oman by time-domain electromagnetic sounding," Hydrogeology Journal, vol. 6, no. 3, pp. 383-393, 1998.

[13] P. M. Soupios, M. Kouli, F. Vallianatos, A. Vafidis, and G. Stavroulakis, "Estimation of aquifer hydraulic parameters from surficial geophysical methods: a case study of Keritis Basin in Chania (Crete-Greece)," Journal of Hydrology, vol. 338, no. 1-2, pp. 122-131, 2007. 
[14] A. Neal, "Ground-penetrating radar and its use in sedimentology: principles, problems and progress," Earth-Science Reviews, vol. 66, no. 3-4, pp. 261-330, 2004.

[15] A. Zaennudin, D. Wahyudin, M. Surmayadi, and E. Kusdinar, "Forecasts of volcanic eruption danger Ijen in East Java," Jurnal Lingkungan dan Bencana Geologi, vol. 3, no. 2, pp. 109-132, 2012.

[16] S. T. Sidarto and D. Sudana, Geological Map of the Quadrangle Banyuwangi Java 1707-4, Scale 1:100.000, Geological Research and Development Center, Bandung, Indonesia, 1993.

[17] K. Sitorus, Volcanic stratigraphy and geochemistry of the Ijen Caldera Complex, East Java, Indonesia [M.S. thesis], Victoria University of Wellington, Wellington, New Zealand, 1990.

[18] N. P. Claude, N.-M. Théophile, A. S. Patrick, and K. T. Crepin, "Evidence of iron mineralization channels in the Messondo area (Centre-Cameroon) using geoelectrical (DC \& IP) methods: a case study," International Journal of Geosciences, vol. 5, no. 3, pp. 346-361, 2014.

[19] M. N. Tijani, O. O. Osinowo, and O. Ogedengbe, "Mapping of sub-surface fracture systems using integrated electrical resistivity profiling and VLF-EM methods: a case study of suspected gold mineralization," RMZ-Materials and Geoenvironment, vol. 56, pp. 415-436, 2009.

[20] A. S. Ogungbe, J. A. Olowofela, O. J. Da-Silva, A. A. Alabi, and E. O. Onori, "Subsurface characterization using electrical resistivity (Dipole-Dipole) method at Lagos State University (LASU) Foundation School, Badagry," Applied Science Research, vol. 1, no. 1, pp. 131-145, 2010.

[21] J. E. Sunday, Appication of geolectrical resisitivity imaging to investigate groundwater potential in Atan, Ogun State Southwestern Nigeria [M.S. thesis], College of Science and Technology, Covenant University, Ota, Nigeria, 2012.

[22] M. H. Loke and R. D. Barker, "Rapid least-squares inversion of apparent resistivity pseudosections by a Quasi-Newton method," Geophysical Prospecting, vol. 44, no. 1, pp. 131-152, 1996.

[23] M. S. Barseem, T. A. A. El Lateef, H. M. E. El Deen, and A. A. A. A. Abdel Rahman, "Geoelectrical exploration in South Qantara Shark area for supplementary irrigation purpose-Sinai-Egypt," Hydrology: Current Research, vol. 6, no. 2, pp. 1-10, 2015.

[24] D. H. Griffiths and R. D. Barker, "Two-dimensional resistivity imaging and modelling in areas of complex geology," Journal of Applied Geophysics, vol. 29, no. 3-4, pp. 211-226, 1993.

[25] M. Loke, I. Acworth, and T. Dahlin, "A comparison of smooth and blocky inversion methods in 2D electrical imaging surveys," Exploration Geophysics, vol. 34, no. 3, pp. 182-187, 2003.

[26] M. Ezersky, "Geoelectric structure of the Ein Gedi sinkhole occurrence site at the Dead Sea shore in Israel," Journal of Applied Geophysics, vol. 64, no. 3-4, pp. 56-69, 2008.

[27] E. Novakova, M. Karous, A. Zajícek, and M. Karousova, "Evaluation of ground penetrating radar and vertical electrical sounding methods to determine soil horizons and bedrock at the locality dehtaře," Soil and Water Research, vol. 8, no. 3, pp. 105-112, 2013.

[28] A. P. Annan, "GPR - history, trends, and future developments," Subsurface Sensing Technologies and Applications, vol. 3, pp. 253-270, 2002.

[29] S. D. Smith, J. B. Legg, T. S. Wilson, and J. Leader, Obstinate and Strong: The History and Archaeology of the Siege of Fort Motte, University of South Carolina, Columbia, SC, USA, 2007.

[30] OKM Ortungstechnik GmbH, User's Manual: FUTURE 2005, 2007, http://www.okm-gmbh.de.
[31] L. B. Conyers and J. Leckebusch, "Geophysical archaeology research agendas for the future: some ground-penetrating radar examples," Archaeological Prospection, vol. 17, no. 2, pp. 117-123, 2010.

[32] M. H. Loke and R. D. Barker, "Practical techniques for 3D resistivity surveys and data inversion," Geophysical Prospecting, vol. 44, no. 3, pp. 499-523, 1996. 

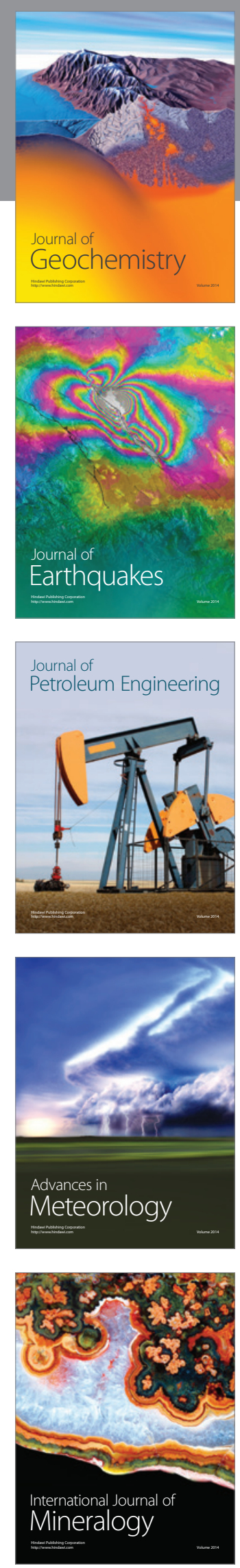
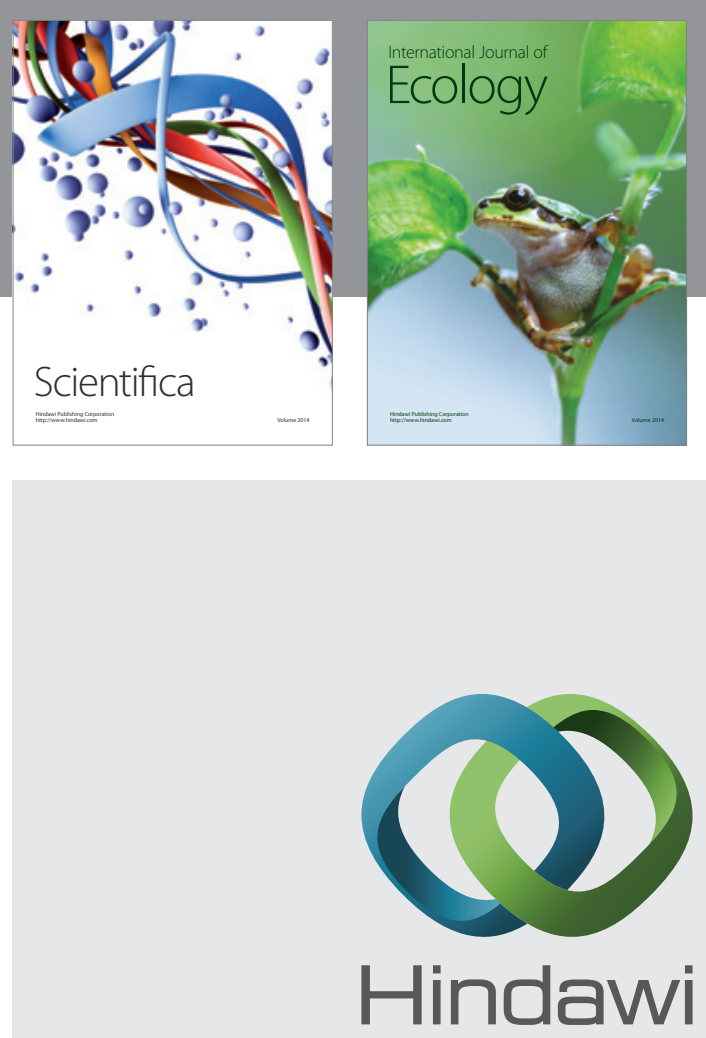

Submit your manuscripts at

http://www.hindawi.com
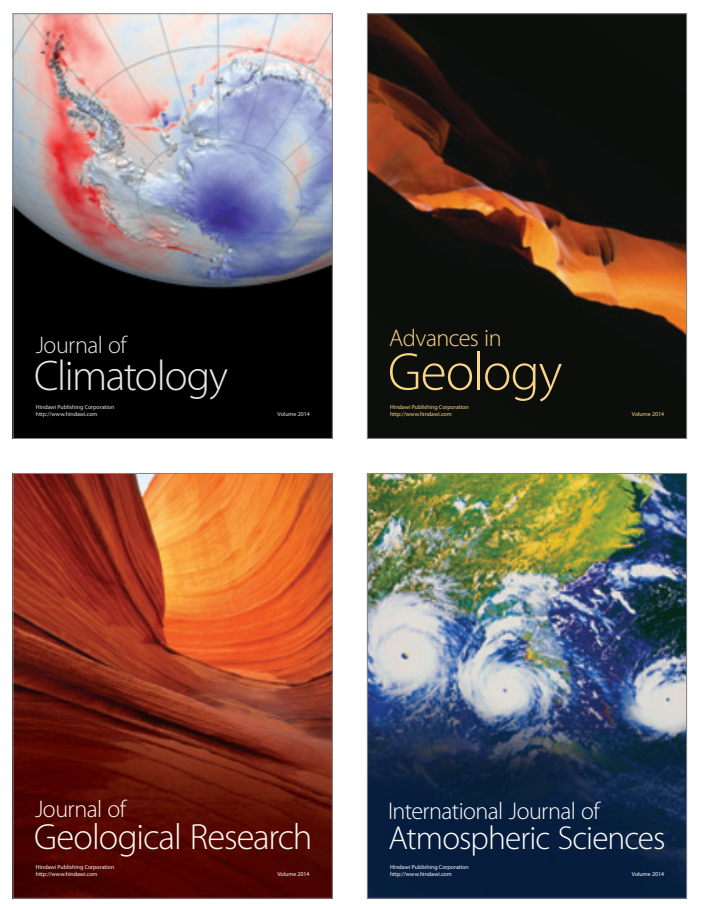

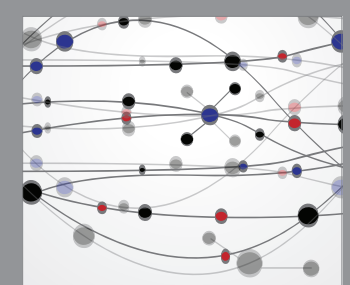

The Scientific

\section{World Journal}
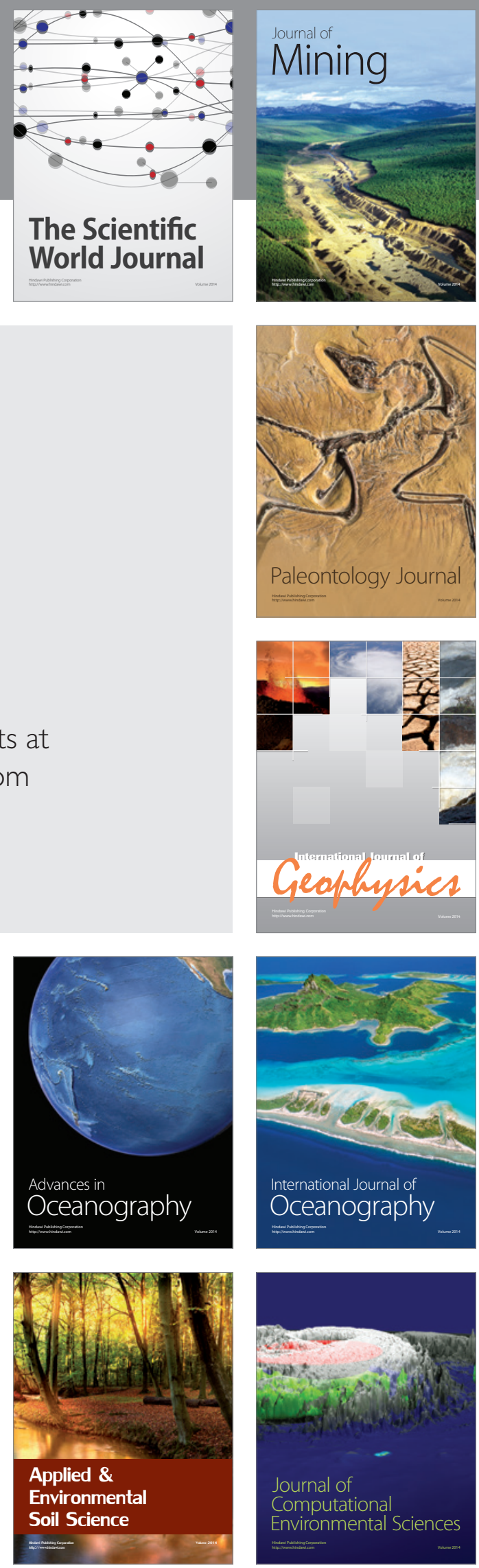